\title{
The "Global salt cycle": Formation of giant salt accumulations, a result of subduction, mantle upwelling, and rifting
}

\author{
Hans Konrad Johnsen ${ }^{1}$ Hakon Ruesltten ${ }^{2}$ Martin Torvald Hovland ${ }^{3}$ \\ ${ }^{1}$ Independent Research Fellow, Stjoerdal, N-7502, Norway, \\ ${ }^{2}$ Independent Research Fellow, Trondheim, N-7049, Norway, \\ ${ }^{3}$ Independent Research Fellow, Sola, N-4055, Norway,
}

\section{Abstract}

The main objective of this communication is to describe the 'Global Salt Cycle'. Giant salt accumulations are commonly found along continental margins of former rifts. The first stage in the accumulation process is saturation of newly formed oceanic crust with seawater. Final mobilisation and accumulation of the salts occurs during rifting, localised in the vicinity of relict subduction zones.

Oceanic crust is created along the spreading ridges in the deep oceans of the Earth. It exchanges mass and energy with seawater in hydrothermal circulation cells that penetrate deep into the new and fractured crust. Water-rock interactions include the formation of hydrated and hydroxylated minerals, e.g., serpentinites and clay minerals. By incorporating hydroxyl groups and water in their crystal lattices, the salinity of remaining brines increases. Subduction of oceanic crust and serpentinised lithosphere transports water, hydrated minerals, and marine salts deep into the crust and mantle. Upon pressurisation and heating of the subducting slab, different parts of this water are expelled at different depths/temperatures. The resulting fluids will contain salts brought in with the slab, as well as new salts formed by water-rock interaction. The combination of elevated pressures and temperatures, water, salinity, and $\mathrm{CO}_{2}$, create permeability in the normally impermeable, peridotitic mantle, by altering the fluid-rock dihedral angles of mineral grains. This P/T-determined intergranular permeability allows ascent of saline fluids, under lithostatic pressure, within the mantle wedge, or the slab itself. The fluids produce a mechanically weakened and buoyant zone within the mantle wedge due to high pore pressure between mineral grains and reduced mantle density. During the lifetime of a subduction zone, a substantial accumulation of saline fluids within the mantle wedge and crust, is evident.

Deep, fluid reservoirs accumulate between the subduction trench and the volcanic front. They may exist for hundreds of millions of years, even after the extinction of the subduction zone. Saline fluids may escape to the surface along deep faults, due to overfilling of available pores/fractures.

Fluids within the mantle wedge may form rock melts or exist as supercritical, mineral rich fluids. The combination of reduced pressure due to rifting, and a saline and buoyant mantle, 
creates a mantle circulation that brings the accumulated, saline fluids, to crustal levels. Salts will therefore accumulate during initial stages of rifting as a result of massive fluid expulsion, phase change and boiling of mantle fluids. No extra energy is required to produce phase change and boiling. The result is formation of solid salts or dense brines/slurries invading fractured crustal rocks, or escaping to the surface/seabed. This process may take place both before and after the sea has invaded a continental rift.

\section{Keywords}

Global salt cycle; Wilson cycle; Giant salt accumulations; Subduction; Rifting; Mantle; upwelling; Hydrated mantle; Hydrothermal salt expulsion; Hydrothermal circulation; Basin subsidence; Supercritical fluids; Phase separation; Saline brine; Salt diapir; Bedded salts; Inherited composition; Inherited structures; Lower crustal body; Electrical conductivity; Magnetotelluric method; Seismic velocity; Brittle-ductile behaviour; Continental crust formation; Oceanic crust formation; Hydration of oceanic crust; Serpentinization; Volcanism; Mineral solubility.

\section{Introduction}

All elements currently included in salt accumulations were initially part of those involved in the formation of the Earth. Most of these elements were incorporated into the Earth's mantle. Via tectonic processes, water was brought into contact with mantle masses and salts were leached out by water/rock interactions. These salts are dominated by chlorides and became part of the ocean and made it into brine. During later development of the Earth, this seawater encounters the remaining salt forming elements in the deep crust and mantle, during various phases of the Wilson Cycles.

There is general concensus that the large salt accumulations observed on Earth are the result of processes where saline waters or seawater has undergone separation of salt and water. Even so, two seemingly contradictory observations relate to the need for vast amounts of evaporation energy, apparently not readily available from other sources than the sun- and the observation of massive layers of salts in the deep oceans, where the sun does not shine. Starting with seawater, the sun is capable of providing the needed energy, within the appropriate timeframe, but only if the saline waters can completely dry out and not immediately be diluted by influx of more seawater.

To explain the observed salt thicknesses, an explanation based on solar evaporation of seawater, requires unrealistic tectonic processes, involving opening and closing of oceanic basins, often more than fifty times. Even then, the composition of the observed salts is not as might be expected from an oceanic composition.

Furthermore, many salt deposits contain minerals that need high temperature for their formation and many salt deposits are devoid of marine fossils. Both facts point in another direction than an ocean with all its marine life, evaporating at temperatures well below $100^{\circ} \mathrm{C}$. However, the question remains: what other processes might be responsible for the 
formation of large salt accumulations, while maintaining a relatively stable seawater salinity over geologic time.

To explain the 'Global Salt Cycle', different areas of geology, thermodynamics, and fluid behaviour must be applied. Although we have attended to this in some detail, we mainly focus on some important issues from a conceptual standpoint. It is, however, necessary to relate the conceptual model to some field cases that stand out as important and clear examples of certain process elements.

In our earlier work, Hovland et al. Part 1, (2018), Part 2 (2018), we introduced the term 'Hidden Salts' as an expression to describe salts that are circulated within subduction zones and exist in the deep mantle and crust.

The objective of this communication is to explain the nature of Hidden Salts and the Global Salt Cycle (Johnsen et al. 2021). Formation of giant salt accumulations are shown to be intimately related to certain stages of the Wilson cycles:

- Formation of oceanic crust with salts, sediments, and hydrous minerals.

- Subduction of oceanic crust, mineral breakdown, and expulsion of supercritical saline vapours.

- Localised rifting of lithosphere and crust due to fluids, structural and compositional inheritance, ascent of hydrated mantle, lithospheric thinning, and, ultimately, expulsion of salts in uplifted, confined basins, via thermodynamic processes.

- The accumulation of salts within a rift basin diminishes and subsequently ends upon full oceanisation (e.g., Brazil and Angola).

\section{Observations from major salt deposits}

This chapter discusses some pertinent observations that provide evidence for the formation of giant salt deposits as an integral part of the Global Salt Cycle.

\subsection{Diapiric or extrusive salt in the northern Red Sea}

In the northern Red Sea, Mart and Ross (1987) describe up to $40 \mathrm{~km}$ long salt ridges (diapirs?) that rise up to $250 \mathrm{~m}$ above the seafloor. Mart and Ross (1987) concluded: «We suggest that development of diapirs under these minimal overburden conditions was made possible by the high thermal gradients in the area, resulting from the underlying attenuated continental crust and ascending mantle, that prevail in the rift system of the northern Red Sea. Diapiric evolution was also dependent on the extensional tectonic regime, with its numerous normal faults forming weaknesses along which the diapirs could move upwards.»

Salt diapirs in the Northern Red Sea rise above the seabed, even though they are not pushed up by the weight of surrounding sediments and even though the basin is expanding and therefore providing no sideways push on the diapirs. Our conclusion is that the rising salts are a consequence of saline fluid expulsion from the ascending mantle, also mentioned by Mart \& Ross (1987). 
Augustin et al. (2021), presents a new model for the development of oceanic crust in the Red Sea. They conclude that the Red Sea axis is completely underlain by oceanic crust as far north as the Red Sea-Dead Sea transform fault. This implies that the salt diapirs, observed by Mart and Ross (1987) are situated directly on top of the spreading oceanic crust and supports the hypothesis of a mantle source for the salt ridges.

Ligi et al. (2019) interpreted two seismic transects west of the Brothers Island in the Red Sea. It is stated that the area has not undergone tectonic activity since salt deposition. The absence of tectonic activity, minor tilting of underlying basement, a combination of diapiric and bedded salts with no sediments in between the two, and little sediment load on top of the salt, points in the direction of influx of salts from the underlying mantle (Fig 1).

A process involving precipitation from evaporating seawater would have produced bedded salts. The upper salt surface and sediment thickness is not consistent with diapiric movements post salt deposition. Bedded salts and diapiric, therefore, must have formed nearly simultaneously by some other process than plain seawater evaporation.

In our view, saturated hot brines, expelled from the mantle have precipitated salts inside the diapirs during ascent, and also after flowing into mini basins in between diapirs (Hovland et al., 2015; 2019).

Figure 1. Seismic section with interpretation from the Red Sea, west of Brothers Island, showing diapiric structures and bedded salt formed independent of tectonic movements or sediment loading. (Modified from Ligi et al. (2019)). Encircled area shows diapiric structure below point of high sediment loading, inconsistent with formation of diapiric salt structures due to sediment loading.

\subsection{Anomalous salts in the Zechstein formations, Germany}

Braitsch (1971) lists the occurrence of talc, talc/serpentinite, amenite and penninite in Zechstein salt deposits in Germany. All of these minerals are associated with relatively high temperature $\left(\right.$ talc $>300^{\circ} \mathrm{C}$ ) and/or magnesium/aluminium rich environments. These are hardly compatible with the composition of- and conditions for, solar-evaporating seawater.

Braitsch (1971) also lists the occurrence of different gases that are encountered in salt deposits. Among these are hydrogen, helium, neon and radon. These are rare gases in the normal atmosphere and in the ocean, but, even so, they occur within deposited salts.

\subsection{Noble gases in bedded salt inclusions}

An investigation by Bauer et al. (2019) deals with noble gas content of brine inclusions in bedded salts from the Permian Salado formation in New Mexico. This formation and the brines are in the order of 200 Ma years old. Brine inclusions were found to be enriched in both argon and helium relative to atmospheric values. Helium was enriched up to 250 times. Helium is present in the atmosphere as a trace gas ( $\sim 5$ parts per million), and is also rather insoluble in seawater. Thus, it is present only at a level about 2 nano-moles per $\mathrm{kg}$ of seawater. Bauer et al. (2019) also measured the content of nitrogen mixed with the helium 
$\left({ }^{4} \mathrm{He}\right)$. The ratio of helium to nitrogen in inclusions was in the order of 1:250. Knowing that nitrogen constitutes $78 \%$ of the Earth's atmosphere and helium only 5 ppm, this ratio is way too high to reflect salt formation in contact with seawater and atmosphere. The ratio between helium and nitrogen in seawater is also many orders of magnitude smaller than the observed value in inclusions.

The content of ${ }^{4} \mathrm{He}$ is said to be due to alpha decay of naturally occurring radioactive elements; argon comes from the decay of ${ }^{40} \mathrm{~K}$. Whereas this explanation may well be valid, the question of why helium ended up being concentrated relative to nitrogen in brine inclusions in salts, is still intriguing. It is very unlikely that helium has selectively migrated into inclusions occupied with nitrogen, after the formation of the inclusions. The only viable explanation is that both gases were trapped simultaneously within the inclusions. This would exclude both the atmosphere and the ocean as their source. The source must therefore be of hydrothermal origin.

\subsection{Coloured salts in the Klodawa salt stock, Poland}

Tobola (2016) reports on a different kind of observations from fluid inclusions obtained from the Klodawa dome within Polish sections of the Zechstein salts. One of the most striking aspects of the Klodawa salts, is the occurrence of coulored salts, in blue and red, associated with doubly terminated quartz crystals and pyrite. Tobola (2016) points to the association of high temperature, igneous rocks and magmatic solutions, for the formation of blue salts.

Temperature measurements based on inclusions from anhydrite embedded in salts, showed homogenization temperatures, where the most common values were between 350 and $450^{\circ} \mathrm{C}$. Tobola (2016) also observed euhedral, doubly terminated quartz crystals embedded in both halite and anhydrite. Euhedral quartz crystals, crystallize from silica-saturated solutions, often within an anhydrite or dolomite matrix. Euhedral quartz is relatively common in salt deposits around the world if anhydrite or dolomite is present, but according to Albright and Lueth (2003), never observed if aragonite is present. Aragonite is the most common shell-building mineral in marine fauna whereas silica is relatively sparse in normal seawater.

Tobola (2016) also made observations of inherent pressures and fluid phases during entrapment of inclusions, concluding that the large variation is consistent with a hydrothermal system. The hydrothermalism and fluid flow within the Klodawa salt dome is also partially responsible for its deformation and distribution of different salts.

In another paper, Tobola and Wachowiak (2018) studied different aspects within the Klodawa salt dome, albeit in a boracite layer. The observed homogenization temperatures within inclusions in anhydrite crystals varied between $197,8^{\circ} \mathrm{C}$ and $473,8^{\circ} \mathrm{C}$.

The Klodawa salt dome and other salt domes in Poland have mineral beds that are difficult to explain by sedimentary, diagenetic or epigenic processes. Among the minerals found in these zones are; boracite and congolite. Congolite mineral is found in cubic shaped blocks and polyhedric boracite crystals which are also found in the same beds. This indicates crystallization temperatures above $339^{\circ} \mathrm{C}$ (congolite) and above $270^{\circ} \mathrm{C}$ (boracite). 
Tobola and Wachowiak (2018) concluded: «Consequently, conditions typical of hydrothermal systems are suggested by: high homogenization temperatures, a wide range of those temperatures, as well as the presence of inclusions, with their homogenization towards gas». This suggests that the salts and other minerals (e.g. quartz, pyrite, marcasite), were not formed as a result of seawater evaporation, but, rather, by hydrothermal processes occurring within the salt domes.

\subsection{Biostratigraphy of salt beds without marine species}

Machado (2020) applied the concepts of biostratigraphy on salt accumulations. This was performed by sampling sections of salts/anhydrite and carefully dissolve the salts in order to observe what living organisms have been trapped in different layers of the salt. The examined locations were:

- Loulé salt mine in southern Portugal, which is in Early Jurassic mobile salt. Impure halite, coaly shales and dolomitised/silicified gypsum were sampled.

- Souss-Massa salt mine in Morocco - an Early Jurassic non-mobile salt, where core samples from halite and shales were obtained.

- Wieliczka salt mine in southern Poland, which comprises Miocene mobile salt. Several types of salt and interbedded shales were sampled.

- Zechstein salt in northern Poland, where red and grey shales, impure black halite, dolomites and black shales were sampled.

- Santana gypsum quarry in central Portugal, where outcrop samples of recrystallised and re-precipitated gypsum and primary gypsum were obtained.

The conclusion from this study is:

«Overall, assemblages are dominated by spores and pollen and other terrestrially-derived organic particles. This suggests that the salt was being deposited or formed in a terrestrial environment or that sea water was only sporadically present. Normal sea water conditions notably salinity - were probably not the norm as dinoflagellates and other marine organisms are either very rare or totally absent in all the studied samples.»

This conclusion is highly surprising if evapoation of normal seawater was the source of these varied salt accumulations, and confirms that other processes are involved.

\subsection{Hydrothermal and volcanic processes in Dallol salt dome, Afar}

López-Garcia et al. (2020) studied the geology, the magmatic and hydrothermal processes related to the salt accumulations in Danakil, Ethiopia. The Danakil depression is ca. $200 \mathrm{~km}$ long, $50-150 \mathrm{~km}$ wide and down to $120 \mathrm{~m}$ below sea level. The area is very hot and receives less than $200 \mathrm{~mm} /$ year of rain. According to López-Garcia et al. (2020), the explanation for this salt accumulation is as follows:

"The salt plain formed when the northern extremity of an ancient Red Sea arm was closed at the Gulf of Zula (Eritrea) due to uplift and doming preceding the Alid volcano Quaternary magma flows. This closure possibly happened during the Pleistocene and left marine reefs at 
different altitudes $(-30$ to $+90 \mathrm{~m})$, marking ancient shorelines. Subsequent seawater evaporation led to the deposition of a $\sim 2 \mathrm{~km}$ thick salt sequence over several thousand years».

The work recognises the importance of hydrothermal- and magmatic activity in the area and they incorporate numerous observations and data in a new model for the observed salts. A volumetric check on the salt volume in relation to the initially available volume of seawater, was however, not attempted.

The significance of such a calculation is demonstrated by Fig. 2 below. The figure shows that the Danakil depression was once filled with water to the marked 'ancient sea level', and that it is presently nearly filled to the brim with mainly rock salt (halite). We may, therefore, conclude that it would require an unreasonable number of openings and closures to produce the observed amount of salt.

Bishofite is known to precipitate from solution after halite and also adhere crystal water into its structure. It may subsequently melt in this water upon heating beyond ca. $120^{\circ} \mathrm{C}$ (Schofield et al. (2014)). Fig. 2 shows a Biscofite layer that was once positioned on top of the salt. It has later been subjected to tectonic movements due to faulting, salt removal from the mantle, and thermal subsidence in the area. Later arriving salts have been placed on top of this layer, seemingly without reducing the thickness of the halite layer below the bishofite layer. This, and the fact that the more mobile bishofite layer is still present, does not support hydrothermal circulation of halite from below the bishofite layer to the surface. Rather, it supports a process where new salts have been produced from below the existing salt accumulation and caused some of the subsidence, evident in Fig. 2.

Figure 2. Cross section through the Dallol dome across the Danakil depression, with salt deposits, volcanism and former sea level. Modified from López-Garcia et al. (2020). Cross hatched potash beds are possibly invaded by the volcanic sill, resulting in mobilisation of the potash and ascending brine flow.

Although Fig. 2 clearly indicates a magma chamber underlying the Danakil salt deposits, its presence is not regarded by López-Garcia et al. (2020) as related to the salt formation. The presence of an ascending mantle in this region, has been confirmed by Esedo et al. (2012), Chang et al. (2011) and Petrunin et al. (2020).

In our view, the situation in the Dallol region represents one of the typical stages in the development of a salt basin. The initial uplift and isolation from the sea, due to ascent of the mantle, has gradually been replaced by thermal subsidence and continued rifting. Salt deposition has taken place within an isolated basin, during- and after updoming/rifting. See also Ch. 7.

\subsection{Soluble salts deposited in humid environments}

Debure et al. (2019) studied the deposition of highly soluble salts like tachyhydrite and bischofte during the Aptian in the South Atlantic and during the Messinian Salinity Crisis. 
These salts are claimed to be inconsistent with the wet and warm palaeoclimate reconstructed for these periods. Debure et al. (2019) performed numerical simulation of mineral reactions involving serpentinization by sea water. According to these simulations, brines formed during serpentinization would mimic the observed composition of salts from natural environments, as described above.

Scribano et al. (2017) also concluded that abyssal serpentinites might be the source of large salt accumulations. Serpentinites concentrate brines and produce heat over extended periods of time. The subsequent ascent of hot, saline brines to the surface or seafloor, may be a longlasting process, mainly occurring in areas characterized by tectonic and/or magmatic activity.

If brines containing highly soluble salts are reduced in water content, i.e. by water-absorbing serpentinization, the remaining brine may solidify upon cooling below ca. $120{ }^{\circ} \mathrm{C}$, albeit still incorporating crystal water.

\subsection{Isostasy in salt basins}

If salt basins collect and deposit salts from solar evaporation of seawater, this will lead to a successive increase in the load carried by the underlying mantle. As a result, the original seabed will subside. For simplicity, we may assume that seawater has a density of $1 \mathrm{~g} / \mathrm{cm}^{3}$, salt a density of $2 \mathrm{~g} / \mathrm{cm}^{3}$ and the mantle a density of $3.3 \mathrm{~g} / \mathrm{cm}^{3}$. Using these parameters, we may do some isostasy calculations on a salt basin with e.g., an average water depth of $1500 \mathrm{~m}$ above a $900 \mathrm{~m}$ salt deposit.

Deposition of $900 \mathrm{~m}$ of salt (from above), makes the mantle subside by $900 \times 2 / 3.3 \mathrm{~m}=545$ $\mathrm{m}$. However, if this salt replaces $900 \mathrm{~m}$ of seawater, the mantle will sink in by only half this distance, i.e. $273 \mathrm{~m}$. Thus, deposition of $900 \mathrm{~m}$ of salts, replacing seawater, will lead to a net movement of the seabed (on top of the salt) upwards by; $900-273 \mathrm{~m}=627 \mathrm{~m}$. This implies that, if the present water depth is $1500 \mathrm{~m}$, it would have had to be $1500+627 \mathrm{~m}=2167 \mathrm{~m}$, before salt deposition took place, for isostatic conditions to be satisfied.

We may also do some calculations of relevance to a shallow basin (Sabkha) experiencing solar evaporation and salt deposition. If we envision a Sabkha maintaining $1 \mathrm{~m}$ water depth, ending up with a final salt layer of $1000 \mathrm{~m}$ thickness, the following calculations will apply: The load of salts will lower the initial seabed by ca. $1000 \times 2 / 3.3 \mathrm{~m}=606 \mathrm{~m}$. However, the top of salt will be almost $1000 \mathrm{~m}$ higher than this. In other words, the new seabed, on top of the salt, will be almost 400 meters above sealevel.

We conclude that isostatic considerations suggests that major salt deposits cannot form by solar evaporation alone. For solar evaporation to produce the observed salt deposits, a carefully executed interaction between water depth, development of accommodation space, subsidence and salt deposition, is required.

If we consider another scenario, where the salts are deposited by upwelling mantle and hydrothermal flow, no extra load is added to the underlying mantle. Assuming constant density of salt as a function of pressure, moving any amount of salts from below the seabed, on top of the seabed, will initially, leave the water depth unchanged. If the rifting and salt 
deposition is initiated on dry land, it may remain isolated from the sea until thermal subsidence in the mantle sets in. If the distance to the sea is great, an intracratonic, - or lacustrine, salt basin, may develop.

Thus, moving salts into a salt basin from the underlying mantle, provides a sufficient explanation to what is actually observed in nature, without additional, tectonic prerequisites.

\subsection{Concluding remarks on observations from major salt deposits}

This review of pertinent observations clearly points at a more direct link between salt accumulations, high heat flow, magmatic- and hydrothermal activities. The presence of hydrothermally associated minerals in salt deposits (talc, penninite, congolite, boracite etc.), suggests that major salt deposits were formed at elevated temperatures. Furthermore, the fact that no signs of marine life was found in a study covering a large selection of major salt accumulations, excludes solar evaporation of the sea as the primary source for these salt deposits. It is further believed that isostatic considerations, in combination with further understanding of the steps involved in the Global Salt Cycle, will reconcile seemingly inconsistent observations in many salt basins.

\section{Formation of oceanic crust}

\subsection{Hydration and mineral conversion}

New, oceanic crust is formed along the spreading ridges of the deep oceans of the Earth. Typically, hot magma rises to the seabed at substantial water depths where it is invaded by seawater, exchanging mass and energy with seawater, and forming hydrothermal circulation cells that penetrate deep into the cooling and cracking crust.

According to Johnson et al. (2000), the result is a permeable and porous oceanic crust, exceeding $20 \%$ regional porosity, initially filled with seawater. Seawater will react with oceanic crust to form new minerals that consume water. A typical example is serpentinization of deeper sections as they cool below ca. $500^{\circ} \mathrm{C}$. Serpentinization leads to denser brines as only $\mathrm{H}_{2} \mathrm{O}$ is consumed in the process (Debure et al. (2019), Scribano et al. (2017)). Serpentinization is a strongly exothermic reaction that adds heat to the system and increases the ability to form salt and/or brines. Serpentinites, therefore, carry along salts and hydroxylated minerals that combined, may form brines upon later mineral breakdown due to heating.

Several authors have documented the role of sediments, mid-ocean basalts and different minerals in relation to water- carrying capacity (and, therefore, also salts) into the subduction zone (Hacker et al. Part 1 and 2 (2003), Li and Ni (2020)).

Kelly and Delaney (1987) reports analyses of fluid inclusions in hydrothermally altered gabbros recovered near the Mid-Atlantic Ridge, recording temperatures up to $700^{\circ} \mathrm{C}$. At the time, this was the highest temperature recorded in fluid inclusions. Fluid salinities in the high temperature inclusions were more than ten times that of seawater. They concluded that high temperature inclusions may have formed adjacent to an active magma chamber. Kelly and 
Delaney (1987) also report on fluid inclusions from the same area, with considerably lower salinity than seawater, thus also observing evidence for phase changes in the fluid system (see Ch. 7).

In a later paper by Kelly et al. (1992), they present data from aqueous fluid inclusions from the Troodos ophiolite, Cyprus. They claim that these samples may provide the first evidence that generation of high-temperature brines may be common, at depth, in the oceanic crust. The fluid inclusions were sampled from rocks that experienced episodic fracturing events. The earliest fracturing event, at temperatures $>450-600^{\circ} \mathrm{C}$ resulted in entrapment of brine-rich aqueous fluids with salinities of 36-61 wt \% $\mathrm{NaCl}$ equivalent.

As oceanic crust becomes older, it grows thicker and new minerals appear at lower temperature than those experienced at the spreading ridge. During ageing of the crust, the basaltic rocks form phillipsite, smectite, celadonite, analcite, carbonates, and Fe-Mn oxides, etc. Thus, according to Grevemeyer et al. (2018), they increase the amount of bound water at the expense of a porosity reduction from $14 \%-17 \%$ to $4 \%-8 \%$ in mature, uppermost, oceanic crust. However, as the oceanic crust bends downwards into the subduction zone, more pore volume is created in fractures. The result is substantial serpentinization, additional intake- and transport of water and hydroxylated minerals (including salts) into the subduction channel, as reported by Grevemeyer et al. (2018).

\subsection{Formation of brines and salts in newly formed oceanic crust}

A numerical simulation of a submerged hydrothermal system below the seabed, above a magma intrusion, by Hovland et al. (2006a, b), has been shown to produce solid salts.

Similarly, Coumou and Driesner (2009) studied the behaviour of hydrothermal, black smoker systems, at oceanic spreading centers. Using equations describing detailed phase behaviour and circulation of fluids within permeable, hot oceanic crust, Coumou-et al. (2009) were able to predict the development of heavy brines and vapours within the crust, at certain depths (pressures). They also concluded that for certain conditions, the lifting capacity of escaping vapours was not capable of removing these dense brines. The brines, therefore, remain within the oceanic crust until eventually removed by other processes later on.

Thus, the behaviour of seawater, brines, and vapour in circulating systems within an oceanic crust, is reasonably well understood. Fig. 3, from Coumou and Driesner (2009) shows a typical situation where solid salts, brines and vapours are formed due to a combination of thermodynamic conditions, flow conditions and phase behaviour of saline fluids.

Although this simulation is representing only a localised zone around the spreading ridge, the entire oceanic crust will experience similar processes as more and more crust is forming along the ridge. Later processes and maturing of the crust will usually not provide the energy required to dilute the formed brines/waters. However, later and deeper serpentinization may increase the volume and salinity of captured waters. 
Figure 3. Simulation of seawater circulation, phase behaviour, fluid flow, formation of vapour, dense brine, and salt at $4500 \mathrm{~m}$ depth in black smoker system above newly formed oceanic crust. Note that solid halite $(\mathrm{H})$ is formed (red zone in a). $\mathrm{LH}=$ Liquid and Halite; $\mathrm{VH}=$ vapour and Halite; $\mathrm{VL}=$ Vapour and Liquid; L=liquid; V=vapour. (Modified from Coumou and Driesner (2009))

Might hydrothermal circulation of seawater within hot oceanic crust explain the formation of giant salt accumulations? An approximate answer to this question can be obtained by performing some energy calculations. As a rule of thumb, the heat contained in $1 \mathrm{~km}^{3}$ of oceanic crust at $12-1300{ }^{\circ} \mathrm{C}$, roughly contains the energy required to evaporate $1 \mathrm{~km}^{3}$ of seawater (see Weis (2015)). However, evaporating $1 \mathrm{~km}^{3}$ of seawater, will only produce a 15 $17 \mathrm{~m}$ layer of salt over a $1 \mathrm{~km}^{2}$ area. Hence, making salt accumulations by consuming the heat contained in fresh oceanic crust down to $10 \mathrm{~km}$ depth, forms less than $200 \mathrm{~m}$ of salt.

It is, therefore, our conclusion that hydrothermal circulation within newly formed oceanic crust, as simulated by Hovland et al. (2006 a, b) and Coumou and Driesner (2009), cannot alone explain salt thicknesses of 1-5 km as observed in salt basins.

Numerical simulation of hydrothermal circulation relies on many assumptions and simplifications with respect to geometry, mineral reactions and permeability development. Nevertheless, they indicate that oceanic crust is loaded with not just seawater and hydroxylated minerals, but also dense brines that, due to their density, will remain at depth until subduction. If including the observations from the Mid-Atlantic Ridge by Kelly and Delaney (1987), we may assume that subducting slabs of oceanic crust will contain significant amounts of brines with a salinity equal to - or higher than that of seawater.

\section{Subduction of oceanic crust: water- and salt budgets}

The oceanic crust, will upon ageing and cooling, become denser than the underlying mantle. This will usually occur after some 150-200 mill years. By then, the oceanic crust will often have received a layer of sediments on top, mostly along the continental margins. At the subduction trench, some of the sediments pile up to form an accretionary wedge. The waterfilled oceanic crust, its sediments and serpentinized lower crust are bent downwards beneath the adjacent continental crust, or sometimes a less dense oceanic crust.

There is evidence that the oceanic salts and water end up being subducted to great depths in the mantle, and, evidently, the salts returning to the surface as a result of different processes addressed herein.

\subsection{Water- and salt budgets in subduction zones}

In his book 'The devil in the mountain', Lamb (2004) links volcanoes to water-input from the active Andean subduction. He states there is a common thread that runs through all the many aspects of volcanoes of the Andes, - and it turns out to be water. Lamb (2004): “Leonore (Dr. Leonore Hoke) found that many of her gas samples contained a high proportion of water vapor, in addition to many other gases including carbon dioxide, nitrogen, and argonhelium only makes up a very small fraction of the sample. The molten rock at depth is rich in 
this water. This is one of the reasons that these volcanoes are so explosive - it is the high pressure of the superheated water vapor, combined with the sticky nature of the lava, that makes the volcanoes into such an unstable pressure cooker, always on the verge of blowing up".

It is also well known that the addition of water lowers the melting point of rocks. The answer to the question of where this water comes from lies in the isotopes of some of the elements studied by Lamb and his associates. Whereas meteoric water is enriched in light hydrogen, ocean water is relatively enriched in deuterium: "Leonore found that the D/H ratios of her samples was similar to ocean water. Could it be that some of this water comes directly from the ocean? An analysis of the nitrogen provides support for this idea. Leonore found that the proportion of nitrogen gas in the samples, compared with other gases, such as argon, was unlike that of nitrogen and argon in the atmosphere. This feature of nitrogen has been found in gases coming not just from the volcanoes in Bolivia, but from many others in the "Ring of Fire" around the Pacific margin. This strongly suggests that it is a feature related to the subduction process itself. One possible source of the "extra" nitrogen is the cooked-up remains of dead organisms on the sea floor that are known to be rich in nitrogen". Lamb (2004) also points to the fact that on the subsiding Nazca plate, the sea floor lies relatively close to the volcanoes, as the plate slides underneath South America. However, for us, it is not the seawater, as such, that is of highest interest, it is the salts that exist within the subduction zone and, therefore, beneath all continents.

Glassley (2001) has linked the composition of seawater in oceanic crust to salts and brines found in fluid inclusions in eclogites. Eclogites are considered to be a result of deep-seated mineral processes within subduction zones. His important conclusion is as follows:

"Regardless of the fluid volumes, the presence of highly concentrated brines at spreading centers, in ophiolites, within subduction zones, and within deep crustal environments implies that brines are intimately associated with oceanic and continental crust during many phases of their evolution. The effect of these ca. 5-8 mol solutions on phase relationships and processes within crustal regimes deserves further attention".

This implies that fluids and salts in oceanic crusts end up with being subducted to great depths, and also returning to crustal levels.

Van Keken et al. (2011) present estimates of the fluxes of water that are currently being subducted. This water ultimately comes from the sea, and therefore carries salts to great depth beneath the continental crust. As seen in Fig. 4, a substantial amount of water is carried to great depths. A significant amount of this water accumulates in the mantle wedge and lower crust, by mechanisms explained later (Ch. 5).

Figure 4. Predicted $\mathrm{H}_{2} \mathrm{O}$ influx at selected depths in the world's subduction zones (Modified from Van Keken et al. (2011)). 
Shirey et al. (2021) studied the cause for deep earthquakes in subduction zones. They concluded that decarbonisation/melting reactions in the slab crust and dehydration reactions in the slab mantle can provide fluids to the earthquake generation regions between $300 \mathrm{~km}$ and $700 \mathrm{~km}$ depth. This suggests that hydrous fluids are carried deeper than indicated by Van Keken et al. (2011).

In the book edited by Harlov (2018), The Role of Halogens in Terrestrial and Extraterrestrial Geochemical Processes, Ch. 8 (Barnes et al. (2018)), present input/output budgets for halogens in subduction zones by adding the contributions from sediments, altered oceanic crust, and serpentinites. According to this work, the mass of chlorine subducted per year is $13-15 \times 10^{6}$ tons/year. If we assume that most of this chlorine is in the form of sodium chloride, this amounts to roughly $21-25 \times 10^{6}$ tons of salts subducted per year.

Kendrick et al. (2017), present fluxes and reservoirs of chloride during different processes and in different reservoirs within crust and mantle. Estimates of subducted chlorine in this study is 1.6-3.5 $\times 10^{6}$ tons/year. This translates into a subduction of $2.6-4.5 \times 10^{6}$ tons/year of $\mathrm{NaCl}$.

These numbers are quite different from the numbers by Barnes et al. (2018). The difference in values stems from different estimates on the content of chlorine in subducted serpentinites and crust. It is more of a surprise that Kendrick et al. (2017) claim that the resirculated volcanic output of chlorides is nearly $50 \%$ greater than the input in subduction zones.

However, Kendrick et al. (2017) also claim that $80 \%$ of the water and heavy halogens on Earth, are already stored in crustal reservoirs. Hence, there should not be much addition of extra halogens in the output from the volcanoes. Two possible sources of error might exist in the data input used by Kendrick et al. (2017). Their estimate of carried water and salts in serpentinites in subduction zones might be too low. Or, since Kendrick et al. (2017) only consider halogen output carried by volcanic basalts, either from oceanic island basalts or mid ocean ridge basalts, they might also miss another form of output via non-volcanic processes and hydrothermalism. Interestingly, Kendrick et al. (2017) list the total mass of halogens found in all evaporites and crustal brines as follows: Evaporites: $30 \pm 5 \times 10^{15}$ tons, Crustal brines: $60 \pm 30 \times 10^{15}$ tons.

If we, for simplicity, assume that all halogens are bound in $\mathrm{NaCl}$, the approximate numbers are $50 \pm 7 \times 10^{15}$ tons and $100 \pm 50 \times 10^{15}$ tons of $\mathrm{NaCl}$. In other words, there is a huge uncertainty with respect to the amounts of halogens/salts hiding in the subsurface of the crust and mantle, which might even contain more salts than the sum of all known evaporite accumulations.

Magni et al. (2014) estimates that the global input of water into the deep mantle through geologic time equals $7 \times 10^{14}$ tons/Myr. This amount does not include the water (74\%) released from subducting slabs above $150 \mathrm{~km}$ depth. If we include all the water and accept their assumption that the present time subduction mechanisms have been around for $2.8 \mathrm{Gyr}$, the amount of salts carried down with this water into the subsurface, is in the order of $2.5 \mathrm{x}$ $10^{17}$ tons. Much of this salt has already resurfaced, but a considerable amount of salt will still be hiding in the deep crust and mantle, due to ongoing subduction. 
Many authors have focused on determining the water flux into subduction zones, usually without mentioning salts. It is, nevertheless, possible to make an estimate of the amount of salt transported down within the Andes subduction zone, based on the work by: Manning (2004), Van Keken et al. (2011), Facenna et al. (2017) and Cagnioncle et al. (2007).

If we consider a subducting slab in South America, $1 \mathrm{~km}$ wide and $5 \mathrm{~km}$ thick (not including serpentinized lower crust). We assume a seawater saturated porosity of $5 \% *$, containing $3.5 \% * *$ salt. A total of $2000 \mathrm{~km}^{* * *}$ of oceanic crust is assumed to have disappeared beneath the Andes.

*) Manning (2004) estimates water content in subducting slabs to be ca. $5 \%$ by weight, or ca. $10 \%$ by volume. (For simplicity, we will assume that salt and rocks both have a density double that of water: $2 \mathrm{~g} / \mathrm{cm}^{3}$ ). These numbers are compatible with those of Cagnioncle et al. (2007).

**) Hydrothermal processes, serpentinization and other mineral reactions in oceanic crusts and lithosphere, will increase actual salt content in a subducting slab.

***) Facenna et al. (2017) estimate that subduction under South America has removed between 2200 and $7800 \mathrm{~km}$ of oceanic crust.

An approximate answer to our question is therefore: $1 \times 5 \times 0.1 \times 0.035 \times 2000 \mathrm{~km}^{3}=$ $35 \mathrm{~km}^{3}$ (or $1.8 \times 10^{10}$ tons) of salt, per $1 \mathrm{~km}$ width of the slab.

If we add the salt content in serpentinized lower crust to our calculation, the amount of subducted salts increases substantially. As shown below, this addition might even be justified in many subduction zones.

Cai et al. (2018) have studied the Mariana subduction zone using advanced seismic interpretation methods to determine the degree of hydration of the subducting slab and its serpentinites in particular. They conclude that the influx of water might be 4.3 times greater, and the volumes subducted below $100 \mathrm{~km}$ depth, 3 times greater, than previously assumed. The reason for this is the interpretation of a thick, serpentinised layer in the subducting slab. This layer was estimated to be $24 \mathrm{~km}$ thick, which is a lot more than previous estimates. Grove et al. (2006) also report findings that indicate serpentinization down to $25 \mathrm{~km}$ depth in subducting slabs.

Worzewski et al. (2010) investigated the Costa Rican subduction zone and estimated a $20 \mathrm{~km}$ thick hydrated zone within the subducting slab.

While it might not be possible to extrapolate such results to all subduction zones, the above studies and calculations prove that there is still considerable uncertainty with respect to subducted masses of both salts and water - and the final estimates for the input and output of salts, might end up being much larger than present estimates.

In conclusion, it is safe to assume that considerable masses of salt have been-, and are still subducted beneath continents, or beneath low-density oceanic plates. There is also evidence, as shown later, that a considerable part of the salts on Earth are found in non-volcanic parts of the crust and mantle. 


\section{Observing saline fluids in crust and mantle}

\subsection{Properties influencing data from crust and mantle}

In order of mapping out fluid systems in the subsurface, different geophysical tools may be applied. Physical properties of crust and mantle at different depths (pressure and temperature), fluid contents, fluid properties, the interaction between fluids and rocks, will influence geophysical responses and should be considered during interpretation of geophysical data. Data collected from deep crustal wells may constrain and enhance this interpretation. In this chapter, we will address some observations in crust and mantle.

\subsubsection{Mechanical properties of the mantle and crust}

Fluid movement in rocks, is affected by the mechanical properties of the rocks. Low permeability, ductile rocks may contain static intragranular fluids. Fluid flow in impermeable, ductile rocks, normally involves diapiric flow of both rock and fluids at high pressure. If intragranular permeability is present, fluids may move more freely in both ductile and brittle rocks. Within brittle rocks, fluids may move within permeable zones between mineral grains, or in fractures. The fractures may be created by elevated fluid pressure (hydraulic fracturing). Thus, anticipated rock/fluid properties at certain depths, will aid the interpretation of collected data.

In general, crustal rocks have increased yield strength with depth. However, at depth, the temperature increases, which has consequences for mineral strength and breakdown of hydrous minerals. Thus, crustal rocks, at certain depths transform from being brittle, strong rocks, into becoming ductile. This general behaviour is true also for the underlying mantle.

Because the mantle has a mineral composition different from the crust, there is a sudden increase in strength at the border between crust and mantle, the Moho. However, at greater depth, below the Moho, the change form brittle to ductile mantle also takes place.

Simplified, general properties of crust and mantle are presented in Fig. $5 \mathrm{a}$ and b, below.

Figure 5a and b. Depth-dependent rock strength properties of a) oceanic- and b), continental lithosphere. (Modified from Allen and Allen (2005)).

The actual mechanical properties of the crust can be measured in situ, in deep wells and by observation and analysis of faults and fracture zones. Behr and Platt (2014) performed measurements on normal-, thrust-, and strike-slip faults. They indicate that maximum crustal strength is reached at temperatures between 300 and $350^{\circ} \mathrm{C}$. Their results confirm that parts of the continental crust are stressed, close to failure, down to the brittle-ductile transition, where deformation transitions from frictional sliding to crystal-plastic deformation and ductile flow. Pore pressures from fluids within the rock will reduce its strength. Breakdown of clay minerals at increasing temperatures release water, increase pore pressures and, therefore, reduce internal friction. Thus, mineral composition will influence the change in mechanical 
properties with depth. The sustained pore pressure due to breakdown of clay minerals may exist at temperatures between ca $100^{\circ} \mathrm{C}$ and ca $260{ }^{\circ} \mathrm{C}$.

In addition to temperature, dictating brittleness and ductility, fluid content, pore fluid pressure, and fluid connectivity play major roles in determining how a rock will respond to stress. In a brittle rock, high fluid pressures internally, may cause the rock to split and create fracture porosity and fluid connectivity (hydraulic fracturing). The direction of such fractures will depend on the general stress excerted on the rocks from previous and present tectonic- or other forces. In volcanic systems, fluids and magma produce abnormal temperature gradients and stress in regions around the magma reservoirs. This will inevitably lead to local zones where ductile and brittle rocks do not follow the general behaviour shown in Fig. 5.

High fluid pressures acting on ductile rocks may cause plastic flow of the rocks and eventually diapiric flow into the brittle parts, thereby creating shallow eartquakes.

For crustal rocks situated in an intracratonic location, the brittle-ductile transition is normally located at a depth between 10 and $17 \mathrm{~km}$ (Behr and Platt (2014)) depending on temperature gradient, crustal mineralogy etc. An accretionary wedge on top of a subduction zone will not obey this general rule, as it is much cooler and usually consist of soft sediments, rather than crystalline crust.

There is no general rule determining the depth where the transition between brittle and ductile behaviour occurs in the mantle of a continental lithosphere, also due to differences in crustal thickness. Generally, the change takes place at around 40-50 km depth, - also depending upon temperature conditions.

A pure oceanic lithosphere will have similar variations in mechanical properties with depth. The transition from brittle to ductile behaviour is generally occurring at around $30 \mathrm{~km}$ depth (Fig. 5).

\subsubsection{Permeability created by saline fluids in the mantle}

As shown later, magneto-telluric measurement of conductivity in deep crust and mantle, indicate a major conductive zone above virtually all subducting slabs, from more than $120 \mathrm{~km}$ depth and upwards. The conductivity and its connectivity over several tens of kilometres is created by fluids and melts, in permeable channels between mineral grains, for reasons explained below. The situation is illustrated in Fig. 6 .

Figure 6. Interconnected, conductive fluids and melts between mineral grains made possible by low dihedral angle between mineral grains. (Modifed from Ghanbarzadeh et al., 2017).

The conditions responsible for this interconnected porosity have been studied in the laboratory using relevant minerals, fluids, temperatures, and pressures. Dihedral angles less than $60^{\circ}$ will open up continuous pore systems between mineral grains and create permeability (Fig.6). 
Watson and Brenan (1987) performed laboratory experiments on dunite and quartz at a temperature range of $950-1150^{\circ} \mathrm{C}$ and a pressure of $1 \mathrm{Gpa}$. The addition of solutes $(\mathrm{NaCl}$, $\mathrm{KCl}, \mathrm{CaF}_{2}, \mathrm{Na}_{2} \mathrm{CO}_{3}$ ) to $\mathrm{H}_{2} \mathrm{O}$ was found to cause a major decrease in the dihedral angle of the mineral grains in the quartz/fluid system (to values as low as $40^{\circ}$ ), but had no effect on fluid wetting in dunite. Tests on upper mantle conditions and different felsic compositions, or by adding $\mathrm{CO}_{2}$ to the fluid, produced dihedral angles of up to $80^{\circ}$, that is,- nonpermeable conditions.

Holness and Graham (1991), performed experiments on calcite and the fluid system $\mathrm{H}_{2} \mathrm{O}-\mathrm{CO}_{2}-\mathrm{NaCl}$, between $1 \mathrm{kbar}$ and $2 \mathrm{kbar}$, and $550-750{ }^{\circ} \mathrm{C}$. In the calcite-calcite- $\mathrm{H}_{2} \mathrm{O}$ system, the dihedral angle was found to decrease steadily with addition of $\mathrm{NaCl}$ from a value of about $80^{\circ}$ (pure water), to $44^{\circ}(60 \mathrm{wt} \% \mathrm{NaCl})$. The $\mathrm{CO}_{2}-\mathrm{H}_{2} \mathrm{O}$ system was found to behave differently. Adding $\mathrm{CO}_{2}$ to the system produced a minimum dihedral angle of $50^{\circ}$ at a mole fraction of $\mathrm{CO}_{2}$ of 0.5 . Pure $\mathrm{CO}_{2}$ and $\mathrm{H}_{2} \mathrm{O}$ in the system produced angles of $90^{\circ}$ and $80^{\circ}$ respectively. Thus, the permeability in a calcite system will be very sensitive to the concentration of $\mathrm{CO}_{2}$ or $\mathrm{NaCl}$ in the fluids. Huang et al. (2020) found a similar relationship between dihedral angle, $\mathrm{NaCl}, \mathrm{CO}_{2}, \mathrm{H}_{2} \mathrm{O}$, and olivine when magnesite and orthopyroxene was present. The presence of orthopyroxene and magnesite was attributed to a reaction between olivine and $\mathrm{CO}_{2}$. Low dihedral angles were observed in this system above $1 \mathrm{GPa}$ pressure and $800{ }^{\circ} \mathrm{C}$.

Holness (1992) presents results from similar studies on quartz systems exposed to $\mathrm{CO}_{2}$ and $\mathrm{NaCl}$ at $800{ }^{\circ} \mathrm{C}$ and a range of pressures from $1 \mathrm{kbar}$ to $15 \mathrm{kbar}(0.1-1.5 \mathrm{GPa})$. Increasing pressure was found to increase the dihedral angle in both pure $\mathrm{H}_{2} \mathrm{O}$ systems and $\mathrm{CO}_{2}$ systems. However, in the pure water system, the dihedral angle decreases with pressures exceeding 6 kbar (0.6 GPa), until angles less than $60^{\circ}$ are reached between 9 and 10 kbar (0.9-1.0 GPa).

Kenji et al. (1998) studied the dihedral angles in water-wet forsterite at 3GPa and 5Gpa and $1000{ }^{\circ} \mathrm{C}$. The observed dihedral angles were decreasing with increasing pressure and observed to be between $48^{\circ}$ and $40^{\circ}$. Kenji et al. (1992) conclude that a network of interconnected pores in forsterite is only present at pressures exceeding $2 \mathrm{GPa}$.

Holness (2006) measured the melt-solid dihedral angles in a range of igneous rock types including: picrite, basalt, phonolite, andesite, and rhyolite - and the minerals: quartz, leucite, plagioclase, olivine, amphibole and clinopyroxene. Low dihedral angles between $20^{\circ}$ and $40^{\circ}$ were measured for all rocks and minerals. Thus, at the depths where high conductivity and melt production is observed, countinuous strings of saline fluids or melts are present. Fluids are known to lower the solidus temperature of rocks and minerals. The absorption of fluids into the melts may produce single phase melts where presence of fluids is only indicated by rock density or melt temperature.

Permeability in the mantle is caused by reduced dihedral angles as a function of fluid salinity, pressure and temperature. The permeability will exist until one or more of these parameters are changed, or the hydrated mantle itself is ascending. The hydrated mantle might, therefore, be preserved for millions of years and influence the location of later rifting. 


\subsubsection{Electrical properties in crust and mantle}

Fluids and salinity may be indicated by electric conductivity measurements, even below 100 $\mathrm{km}$ depth, using magneto-telluric (MT) methods. MT measurements are performed by placing sensitive equipment at the surface and measuring the electromagnetic response of the inner Earth to variations in the solar wind. Using long networks with many sensors, makes it possible to determine the depths to different conductive regions in crust and mantle. Using many sensors over an area, makes it possible to obtain a three-dimensional depiction of the conductivity within the Earth`s interior. Some minerals, interconnected fluids, and rock melts show up as increased conductivity zones within the crust and mantle.

Electric currents are transmitted in several ways in rock systems. In metallic conductors or graphites, currents flow by moving electrons from atom to atom. This creates an instantaneous flow of electric current across the entire conductor.

Silicate minerals behave more like semiconductors, where "impurities" in the minerals occur where the mineral has substituted ions that have a different valence than the rest. A typical example is clinopyroxene, which contains both ferrous and ferric iron in the crystal lattice. This creates electronic "holes" in the mineral that can jump around and respond to electromagnetic influences. The change in valence by an oxidation of $\mathrm{Fe}^{2+}$ to $\mathrm{Fe}^{3+}$ can be caused by the influence of oxygen in water molecules. Both hydration and hydroxylation are sensitive to facies changes and changes in pressure and temperature will therefore affect the conductivity of some minerals.

Hydrogen may also play a role, as protons may easily move around in a mineral lattice in much the same way as electrons or "holes" do. Finally, currents may be transmitted by moving ions dissolved in fluids. However, ions from salts or minerals dissolved in fluids, cannot move inside solids and therefore may accumulate on mineral grain surfaces. The combined effect of electronic currents and ionic transport will, therefore, lead to capacitance as well as conductance within the rocks. The conductivity then becomes frequency dependent and careful analysis is required to interpret the system correctly. Fluids increase their conductivity up to a certain limit if more ions are dissolved. The phase behaviour of water and salts, therefore, puts important constraints on the system. Solubility of salts in water, as a function of pressure and temperature, is discussed in a later chapter.

At certain conditions within the mantle, the capacity to incorporate water into the minerals is high and, therefore, excludes the possibility of free fluids. As melts require elevated temperatures and as elevated conductivities require larger amounts of melting, additional information, or a geologic model might make it possible to differentiate between fluid solutes and melts. Knowing the pressure at certain depths based on known density of rocks, and temperature derived from temperature gradients, allows the determination of facies, and, thus, the possible cause of observed conductance.

Bedrosian (2007) explains phenomena leading to variations in conductivity of fluids/melts in mantle and crust at different pressure- and temperature conditions. For salt solutions, fluid conductivity generally increases with higher concentration. At very high concentrations (30$40 \mathrm{wt} \%$ ), conductivity begins to decrease, as the brine starts behaving like molten salt (with 
low conductivity). A given brine, at a given pressure, will increase in conductivity until 300 $400{ }^{\circ} \mathrm{C}$, due to increased ionic mobility caused by the decreasing viscosity of water. Beyond these temperatures, conductivity begins to fall again. Fluid conductivity increases with pressure at higher temperatures.

Conductivities at upper- and mid-crustal conditions will generally be 1-30 S/m (Siemens per metre), with a value of $100 \mathrm{~S} / \mathrm{m}$ for hypersaline brines, i.e., $25 \mathrm{wt} \% \mathrm{NaCl} . \mathrm{CO}_{2}$ may also contribute to fluid conductivity within the ductile lower-crust. When pore fluids approach lithostatic pressure, $\mathrm{CO}_{2}$ can be present at concentrations approaching $20 \mathrm{~mol} \%$ and react with $\mathrm{H}_{2} \mathrm{O}$ to form $\mathrm{H}_{2} \mathrm{CO}_{3}$. Dissociation reactions lead to the formation of bicarbonate ions in concentrations large enough to increase fluid conductivity by several orders of magnitude. Thus, observation of high conductivity in the crust, where conditions do not allow melting, might be caused by saline fluids containing $\mathrm{CO}_{2}$. As explained earlier, high conductivities might also be the result of mineral facies, hydration, and oxidation states.

\subsubsection{Factors influencing seismic response and earthquakes}

Fluids within rocks at depth only transmit pressure waves. Hence, shear waves are slowed down when encountering fluid-filled porosity in a rock system. The actual values of, or ratio between, pressure wave velocity $(\mathrm{Vp})$, and shear wave velocity (Vs), will therefore tell something about the fluid/melt content of the rocks. However, fluids often have some compressibility that makes the actual geometry of pores or fractures of importance for the shear wave transmission. Porosity in the form of narrow fractures will slow shear waves less than intergranular volumes with a more spherical shape. Again, the geological model must tell you if the rocks are likely to be brittle or ductile, melts or solids, in order to make conclusive interpretations from measurements and observations. This is also valid when interpreting earthquake signals to seismologic stations.

Earthquake signals are normally produced by sudden deformation and displacement of rock bodies caused by mechanical stress or sudden changes in fluid pressure. Shallow earthquakes are often caused by hydraulic fracturing of brittle rock sections due to the impact of volcanic melts or liquids.Ductile rocks often yield more gradually to stresses and often do not produce earthquakes at shallow levels.

The type of minerals and fluid content in rocks will influence their density. The density of crust and mantle can be measured using gravimetric tools. This may indicate that fluids are present within the rocks.

\subsection{Data from wells in the upper crust}

The German superdeep KTB-well was drilled down to $9,1 \mathrm{~km}$ in the vicinity of an extinct subduction zone. A bottom-hole temperature of $265^{\circ} \mathrm{C}$ was encountered. Pump tests reported by Emmermann and Lauterjung (1997), confirmed that pressures of less than $1 \mathrm{MPa}$ (10 bar) above hydrostatic, was sufficient to fracture the rocks and create micro eartquakes, just above $9 \mathrm{~km}$ depth. The conclusion was that the well had been drilled down to the brittle-ductile transition zone. 
Before drilling the superdeep well, a pilot hole was drilled down to $4 \mathrm{~km}$ depth, distanced 200 $m$ away. This enabled testing of permeability between the two wells, at depth. The composition of the fluids varied systematically with depth: groundwater in the upper $650 \mathrm{~m}$, $\mathrm{NaCl}$-dominated fluids of low salinity at intermediate depths, and highly saline, (up to 48 wt $\% \mathrm{CaCl}_{2}-\mathrm{NaCl}$ brines) basement brines below about $3200 \mathrm{~m}$. Fluids were mostly confined to faults and fractures, and these were encountered, even at bottom hole depths, in numerous distinct zones up to several tens of meters thick. According to Emmermann and Lauterjung (1997), the KTB well encountered three main lithological units: paragneisses, metabasites, and a "variegated" series of gneisses and amphibolites. The rocks were found to have been subducted to at least $40 \mathrm{~km}$ depth, before being lifted rapidly to cooler crustal levels. All three units had suffered a pervasive Barrovian-type metamorphism at upper amphibolite facies conditions, $6-8 \mathrm{kbar}$ and $720^{\circ} \mathrm{C}$, at peak conditions of the paragneisses.

Formation pressures determined in brine-containing zones showed a nonlinear increase with depth, probably due to stepwise increases in salinity. The formation pressure of $103 \mathrm{MPa}$ at 9 $\mathrm{km}$ was found to be near-hydrostatic. This, and the fact that experiments proved a hydraulic connection between the pilot hole and the main hole, indicates that fluid pathways were highly interconnected.

The Russian superdeep well drilled in the Kola peninsula reached more than 12,2 km depth (Kozlovsky (1987)). It differs from the KTB well in that it penetrated an intracratonic setting including Precambian rocks. The Kola well also encountered severely stressed and fractured rocks filled with saline fluids and dissolved gases, below $7 \mathrm{~km}$ depth. Temperature at the bottom of the well was $180^{\circ} \mathrm{C}$.

During the drilling of the Russian superdeep wells at Kola, the rocks were found to be highly fractured below ca. $7 \mathrm{~km}$ depth (Kozlovsky (1987)). The expectation of the scientists before drilling, was an encounter with dry granitic rocks at depth. This proved to be wrong. The observed metamorphic facies observed at depth in the well changed from greenschist facies at the top to epidote-amphibolite and amphibolite facies below $9 \mathrm{~km}$ depth. Brines escaping from fractures or released after being mobilised from the mineral structure, showed increasing content of magnesium-, sodium-, calcium- and chloride ions, with depth. A substantial amount of hydrogen, helium, and $\mathrm{CO}_{2}$ was also liberated from the drilled rock.

Hence, both of the superdeep wells, in different tectonic settings, documented that the deeper crust is highly fractured, and brine filled.

Several wells have been drilled deep into the Fennoscandian shield in relation to mining activities. Nurmillmo et al. (1988) studied data from several wells and noted these common features: «- three types of saline groundwater are observed: an uppermost layer of brackish and saline water from 300-900 m depth; saline water and brines from 1000-2000 m depth; and superdeep brines which have been observed to a depth of at least $11 \mathrm{~km}$ in the drill hole on the Kola Peninsula, U.S.S.R. Electrical and seismic studies in shield areas suggest that such brines are commonly present at even greater depths». 
In the academic dissertation by Kietäväinen (2017) on deep groundwaters in eastern Finland, a $2.5 \mathrm{~km}$ deep drill hole has been investigated. Salinity of groundwaters were found to be moderate (less than $15 \mathrm{~g} / \mathrm{l}$ ) down to approximately $1.5 \mathrm{~km}$ and more than $60 \mathrm{~g} / 1$ in the deeper sections below $2 \mathrm{~km}$. The main solutes beeing $\mathrm{CaCl}_{2}$ and $\mathrm{NaCl}$. A deep source for this salinity was, however, not considered.

Several studies have been made trying to explain the origin of the well known hypersaline brines within the Canadian Precambrian shield. Bottomley et al. (2005) studied chemical and isotopic data for deep seated calcium chloride brine from the Miramar Con gold mine near Yellowknife in the Northwest Territory. The objective was to determine whether the brines could be explained by a surface evaporative process or a cryogenic process. The results strongly suggest that the brine salinity is of marine origin. The mechanism responsible for concentrating the hypersaline brine end member was not clear, as evidence exists to support both evaporative and cryogenic processes. Regardless of the concentrative mechanism, the chemical data indicate that the Yellowknife parent brine was concentrated 28- to 30-fold relative to seawater.

Another study by Stotler et al. (2012) on the origin of saline groundwaters of the Canadian and Fennoscandian shield, set out to test the hypothesis of freezing as the main reason for salinity of deep seated fluids. Only the brackish waters of upper sections down to $1000 \mathrm{~m}$, were found to be affected by freezing. Based on isotopic analysis and geochemical data the following was concluded: "It was clear that Canadian and Fennoscandian Shield brines did not evolve as a result of evaporation or the freeze-out process (surficial or in situ); brine evolution is more significant than fluid origin. Physical and geochemical data do not support the hypothesis that shield brines formed cryogenically in glacial marginal troughs». Forming of methane hydrates as part of the process was also considered, but not found to fit the data. A deep origin of the brine was not considered, but the presence of hypersaline brines in the upper crust, remains a fact.

Stober and Bucher (1999) investigated the origin of salinity of crustal fluids in the Black Forest basement in Germany. Two fluid systems have been studied, deep thermal waters and more shallow mineral waters. An interesting observation is made on the composition of the two fluid systems. The shallow fluids are enriched in bicarbonates and depleted in chloride, relative to the deeper sourced thermal waters, indicating that they are the result of two different processes.

Springs producing thermal waters are normally found in granites, whereas mineral waters are located predominantly in gneiss. By observing the ratio of $\mathrm{Cl}$ versus $\mathrm{Br}$ in the thermal waters, it is concluded that they are not the result of dissolution of nearby evaporitic halite deposits, but rather a result of seawater dilution. The conclusion regarding their final composition was found to be a result of surface waters equlibrating with rocks and then mixing with deep, stagnant, saline fluids within the crust. The ratio between $\mathrm{Cl}$ and $\mathrm{Br}$ was shown by Svensen et al. (2001) to resemble that of seawater, even within inclusions from eclogites. A similar conclusion was reached by Glassley (2001). Hence, the source for the stagnant, saline fluids in the Black Forest might, therefore, be very deep. 
Based on the observations presented above it is suggested that the hypersaline fluids observed at crustal levels have a deep origin. The fluids may have migrated into the crust after its formation or been emplaced there as a crustal component. Fluids within fractured crust, may have been injected into the rock from below and caused hydraulic fracturing/earthquakes in the process. Another alternative is expulsion into fractures from pore waters in the native rock. In either case, the source of this saline water must be deep seated.

\subsection{Observations in rocks from lower crust and mantle}

Many authors have confirmed the presence of saline fluids in metamorphic and igneous rocks that have deep origins. A few examples are presented here.

Scambelluri et al. (1997) present data from fluid inclusions embedded in a serpentinite involved in the Alpine subduction. The inclusions formed at $2.5 \mathrm{GPa}$ and $550-600{ }^{\circ} \mathrm{C}$ during partial devolatilization and eclogitization. The inclusions are salt-saturated and contain up to $50 \mathrm{wt} \% \mathrm{Cl}, \mathrm{Na}, \mathrm{K}, \mathrm{Mg}$ and $\mathrm{Fe}$.

Scambelluri et al. (1997) concluded: "The data presented suggest that the seafloor hydrothermal signature was inherited by the eclogitic fluid due to partitioning of chlorine and alkalis into the fluid phase. The presence of salty brines in eclogitized hydrous peridotites can indicate deep recycling of seawater-derived fluids. Hydrous ultramafic systems can therefore act as large-scale carriers of seawater into the mantle."

Mukherjee and Sachan (2009) have analyzed the subduction-related coesite-bearing eclogites of the Tso Morari Complex, Himalaya. These eclogites contain five major types of fluids also including high-salinity brines and low-salinity aqueous fluids. The coesite-bearing rocks are inferred to have been buried to a depth of $>120 \mathrm{~km}$, where they experienced ultrahighpressure metamorphism at ca $750^{\circ} \mathrm{C}$ and $39 \mathrm{kbar}$. The different fluid systems were created during the subduction phase of the observed rocks, as well as their later rise towards the present surface.

Harlaux et al. (2017) made a study of primary fluid inclusions hosted in quartz and topaz from the Beauvoir granite (Massif central, France) and the metasomatized stockwork surrounding the granite. They concluded: «Microthermometric and Raman spectrometry data show that the earliest fluid (L1) is of high temperature (500 to $\left.>600^{\circ} \mathrm{C}\right)$, high salinity (17-28 wt.\% $\mathrm{NaCl} \mathrm{eq})$, and $\mathrm{Li}$-rich $\left(\mathrm{Te}<-70^{\circ} \mathrm{C}\right)$ with $\mathrm{Na} / \mathrm{Li}$ ratios $\sim 5$. LA-ICPMS analyses of L1-type fluid inclusions reveal that the chemical composition of this magmatic-hydrothermal fluid is dominated by $\mathrm{Na}, \mathrm{K}, \mathrm{Cs}$, and Rb, with significant concentrations (101-104 ppm) in raremetals ( $W, \mathrm{Nb}, \mathrm{Ta}, \mathrm{Sn}$, and Li). This study demonstrates that primary fluid inclusions preserved the pristine signature of the magmatic-hydrothermal fluids in the Beauvoir granite but also in the metasomatized W stockwork, despite the distance from the granitic cupola $(>100 \mathrm{~m})$ and interaction with external fluids.»

Harlaux et al. (2017), therefore, document the presence of abundant brines within the ascending, molten granite body.

Svensen et al. (2001) studied the halogen content in fluid inclusions derived from eclogites within the gneiss region of western Norway. Salinities of $15-25 \mathrm{wt} \% \mathrm{NaCl}$ equivalent, was observed in omphasite- and garnet hosted inclusions. They made an important observation 
regarding the apparent nature of the analysed fluids: «The Cl/Br vs. Br characteristics of the fluid inclusions resemble the chemical evolution of evaporating seawater, which might provide a basis for studying halogen mineral-fluid fractionation even at high P-T conditions.»

In other words, brines from depth in subducting systems, might be interpreted as evaporated seawater if only the ratio between $\mathrm{Cl}$ and $\mathrm{Br}$ is considered.

Zedgenizov et al. (2007) present the first direct determinations of the composition of fluid inclusions in diamonds from eclogite xenoliths in the Udachnaya kimberlite pipe. The xenoliths had been exposed to $1150^{\circ} \mathrm{C}$ at $50 \mathrm{kbar}$. The xenoliths were examined and fluid inclusions in clinopyroxene and garnet were analyzed. High values of $\mathrm{Cl}(15-25 \mathrm{wt} \%)$ and $\mathrm{K}$ (10-20 wt $\%)$, carbonates and small amounts of water were observed. This confirms the presence of salts and water in deep crust.

Glassley (2001) performed numerical simulations on fluid-rock equilibria in order to establish conditions and ingredients that would end up producing the observed composition of fluid inclusions from eclogites. Although it is recognised that inclusions may not represent the true, initial salinity due to diffusion and leakage of $\mathrm{H}_{2} \mathrm{O}$, it is nevertheless concluded that the brines remain an order of magnitude higher in salinity than seawater, while maintaining compositional characteristics different form seawater. Glassley (2001) made the assumption that the starting point for brine evolution was seawater and oceanic crust, where primary, igneous minerals are dissolved, while precipitating secondary minerals. This process consumes water due to hydration of new minerals. The brine-mineral system was allowed to evolve through continued, simulated removal of water in the presence of some $\mathrm{CO}_{2}$. Glassley (2001) makes this very interesting observation: «A broad range of feldspar end member ratios were attempted, with the target composition at the end of the reaction process being that of the computed eclogite fluid inclusion chemistry. The results, which provided the best fit consumed 0.04 mol of anorthite and 0.12 mol of potassium feldspar dissolved in seawater, with $93.7 \%$ of the $\mathrm{H}_{2} \mathrm{O}$ removed. The initial product minerals of the seawater-silicate interaction are K-rich nontronite clay, quartz, alunite (a potassium sulfate), and dawsonite (an hydrated sodium-aluminum carbonate). This assemblage (clay-carbonate-quartz) mimics an initial basalt hydration mineral assemblage. As removal of water proceeds, chlorites also form. Upon removal of $>90 \%$ of the $\mathrm{H}_{2} \mathrm{O}$, the final mineral assemblage is anhydrite-dolomite-halite-sylvite, which is similar to the daughter crystal mineral assemblage observed in the fluid inclusions».

Hence, the simulations by Glassley (2001), although simplified, compared to real mineral systems and processes, produced some of the major components found in present day giant salt deposits (e.g., Braitsch (1971)), in chemical equilibrium with the brine composition of fluid inclusions in eclogites from subduction zones.

Kawamoto et al. (2013) studied inclusions i xenoliths from the Pinatubo volcano and found that they have been invaded by moderately saline fluids and $\mathrm{CO}_{2}$. Because of the chemistry of the observed fluids, melting of silicate rocks is not thought to have occurred. This is in contrast to other inclusions with high silica content. $\mathrm{NaCl}-\mathrm{CO}_{2}$-type hot springs are observed in the forearc region of the Southwest Japan arc, also indicating a fluid system ascending from the subduction zone, separate from the fluids transported by volcanic melts. 
The observations above indicate the relationship between fluids released from subducting slabs and fluids observed in the crust. Kawamoto et al. (2013) also document the presence of saline fluid solutions, in addition to the volcanic melts. This is also confirmed by Barnes et al. (2018). They state that salt solutions may increase the melting temperature of minerals and also: "At sufficiently high concentrations of $\mathrm{CO}_{2}$ and salt, this can lead to the creation of two fluid phases, one of which is a brine with a high carrying capacity for metals derived from the slab».

\subsection{Dehydration of subducting slabs and hydration of the mantle}

\subsubsection{Thermodynamics of fluids in the subduction zone}

According to Kawamoto et al. (2012, 2013) and Manning (2004), minerals and water may form supercritical fluids, where dissolved solids and water become one fluid phase. Fluids that are expelled from the slab at sufficiently high temperature and pressure, will be supercritical, mono-phase fluids in equilibrium with the mineralogy at the top of the slab.

During ascent, these supercritical fluid systems $\left(\mathrm{H}_{2} \mathrm{O}\right.$, salt, silicate solutions) will enter the zone of phase separation, where they split into a relatively light vapour with little mineral content and a vapour with higher mineral content. According to Kawamoto et al. (2012, 2013), the denser component after phase separation, will become a basaltic melt. This melt may later mix with the melts ascending from hotter and deeper sections of the subduction zone. The solubility of different minerals within the denser vapour/melt, determines the characteristics of the melts.

According to Shmulovich et al. (2001) the solubility of quartz and albite at 9 kbar and 5$900^{\circ} \mathrm{C}$, decrease with increasing $\mathrm{NaCl}$ concentration, whereas the solubilty of diopside increases with increasing $\mathrm{NaCl}$ concentration. Quartz solubility in $\mathrm{NaCl}$ rich brines does not change with pressure within the tested conditions. Albite was found to have slightly higher solubility than quartz in pure $\mathrm{H}_{2} \mathrm{O}$. For a simplified illustration of supercritical mineral-water behaviour, see Ch. 7.1 on the behaviour of the simpler salt-water system.

The important conclusion related to the present work by Shmulovich et al. (2001), Kawamoto et al. (2012, 2013), and Manning (2004), is the possibility of two fluid-mineral systems coexisting within the mantle wedge, where one of them develops into a secondary melt system. Because temperature and pressure increase very gradually, over time, down the path of subduction, the phase behaviour of all involved components, develops into a spectrum of slightly different fluids. During subsequent ascent the fluid systems will intermingle and also combine with the melt system. These conditions, therefore, can explain the observed variety of salinities and mineral components within fluid inclusions.

\subsubsection{Observed fluid release from subducting slabs}

Magneto-telluric mapping of numerous subduction zones has shown that there are typically three major zones of conductive fluid release during subduction. The first expulsion of conductive fluids takes place at relatively shallow depth of $10-15 \mathrm{~km}$. It is related to clay 
mineral breakdown at temperatures, mostly below $200^{\circ} \mathrm{C}$. The next expulsion of conductive fluids takes place as eclogitization of the slab sets in above $500^{\circ} \mathrm{C}$. These fluids are released at $40 \mathrm{~km}$ depth and deeper, which is normally a low-permeability zone. The major contributor for this fluid is the dehydration of serpentinites located below the basaltic layers and the remaining sediments on top of the slab. Protected by the ductile rocks above, transport of water to greater depths is, therefore, possible.

Continued release of water results from the subsequent breakdown of hydrous minerals as the slab moves deeper. Barnes et al. (2018) state that antigorite stability implies possible transport of water and fluid mobile elements down to $150-200 \mathrm{~km}$ in subduction zones. Typically, antigorite will break down to form chlorite, while releasing water at $650^{\circ} \mathrm{C}$ and above, depending on pressure. Chlorite will dehydrate at ca $870{ }^{\circ} \mathrm{C}$ to form garnet peridotite. (Huang et al. (2019)). Fluids are transported down with the slab and thus, released over a wider depth interval (Cagnioncle et al. (2007)).

A study by Shirey et al (2021) of sub-lithospheric diamonds (that crystallize at $\sim 300-700 \mathrm{~km}$ depth) confirms the ability of slabs to transport and release aqueous fluids, metallic liquids, and/or carbonatitic melt at depths where deep earthquakes also occur.

Thus, fluids released from subducting slabs will influence both the lithospheric- and astenospheric mantle to great depths.

\subsubsection{Fluid ascent in the mantle and crust}

Huang et al. $(2019,2020)$ argue that there is a zone of fluid ascent above subducting slabs that does not lead to melting of peridotite in the mantle wedge, because the temperature is too low. However, the conditions still allow for permeability due to low dihedral angles of peridotite grains when subjected to saline fluids. Their argument is based on new experimental data for depleted, wet peridotite solidus, indicating that it might be up to $1050^{\circ} \mathrm{C}$ at pressures of $1-3$ $\mathrm{GPa}$. According to Huang et al. (2019), the process responsible for saline fluid release is breakdown of antigorite to chlorite. At elevated pressures, this occurs slightly above $700^{\circ} \mathrm{C}$. As seen from Fig. 7, this coincides with conditions where fluid transport through a permeable mantle wedge is possible, due to the existence of dihedral angles between mineral grains of $60^{\circ}$ or less. The permeable fluid-containing zone in the mantle wedge will exist up to ca. 45 $\mathrm{km}$ depth, and ca. $700^{\circ} \mathrm{C}$. Melting occurs when tempertures exceed ca. $1050^{\circ} \mathrm{C}$, and allows the ascent of melts (Fig. 7). Kawamoto et al. (2012) argues that the fluid systems will undergo phase separation above ca $80-90 \mathrm{~km}$ depth and eventually produce a secondary fluid based melt system. This is illustrated by the blue volcano in Fig. 7. It also illustrates the distance between the volcanic front and the observed, conductive fluid reservoirs, as identified by Worzewski et al. (2010).

Figure 7. Fluid release from subducting slabs leading to permeability, ascent of saline fluids and formation of saline fluid reservoirs in mantle and crust. Increasing temperatures along the slab results in increasing rock solubility, a mixed zone of solubles and melts, and eventually the rock melts as observed by volcanic activity. The red triangle (volcano) represents fluid 
derived magma and the blue triangle (volcano) represents melt derived magma. (Modified from Worzewski et al. (2010), Huang et al. (2019), Kawamoto et al. (2012), Belusov (1966).

Fluid release from minerals occurs at lithostatic pressure and will therefore increase intragranular pore pressures if permeability is low. Above the zone of permeability created by salinity, pressure and temperature, fluid pressures will be very high due to continued release of fluids from the slab. To make an estimate of the pressures created at the top of an interconnected, vertical fluid column, we assume that the saline fluids within the interconnected pores, have a fixed density of $1.5 \mathrm{~g} / \mathrm{cm}^{3}$ and the surrounding rocks have a density of $3.3 \mathrm{~g} / \mathrm{cm}^{3}$. The fluids will be pressurized lithostatically at the bottom of the column and therefore create high pressures, both along the column and at the top. On top of a 40-50 $\mathrm{km}$ high, confined fluid column within the mantle wedge, an overpressure of ca. 7200-9000 bar (720-900 Mpa) might be created. As shown by Gueydan et al. (2008) and Behr and Platt (2014), this is comparable to the mantle strength at $700^{\circ} \mathrm{C}$ and a lot more than the strength of the crust. In a real system, the fluid pressures would cause a permeable zone to also widen laterally along the flow path of the fluids.

Thus, the strong and brittle lithosphere will be severely stressed by ascending fluids. As shown in Fig. 5b, the lower crust, directly above Moho, is considered to be weak and ductile.

After breaking through the strong mantle at Moho depth, fluids will pressurize the ductile lower crust and create diapiric flow towards the brittle parts of the crust (Fig.7).

As reported by Kawamoto et al. (2013), Huang et al. (2019, 2020), and confirmed by magneto-telluric measurements (Ch. 5.5, 5.6), the mineral breakdown, and expulsion of saline fluids from a slab at temperatures above $700^{\circ} \mathrm{C}$, will eventually lead to the observed conductive reservoirs, just above Moho. In our opinion this conductive zone represents what is commonly referred to as a Lower Crustal Body (LCB). The LCB will host rocks and minerals that are the result of metamorphic processes in equilibrium with the fluids and physical conditions at this depth.

Continued filling of the observed reservoir above Moho, will eventally lead to invasion of the brittle parts of the crust. As observed by Emmermann and Lauterjung (1997) in the KTB-well, this part of the crust is severely stressed and is easily fractured by slight overpressures. Secondary earthquakes at crustal depths of 5-10 km may signal continued hydraulic fracturing of upper crustal rocks as observed by Wannamaker et al. (2014). Se also https://earthquake.usgs.gov/earthquakes/map.

Over time, the crustal reservoir will become hydrostatic (as observed in deep wells) and the saline fluids will remain in place due to a combination of density and elevation, until overfilling the reservoir or by being liberated by some other process. Regions on Earth with surface altitude below the water table or below sea level, might permit flow of saline fluids into the low parts. If climatic conditions are dry, solid salts will form there (e.g., Dallol, Dead Sea, Quattara, etc.). 
Fluids within the permeable section of the mantle, created by low dihedral angles due to salinity, pressure, and temperature will, therefore, remain in place after the end of the subduction activity.

Ponding of fluids around Moho-depths above subduction zones is also anticipated by Pommier and Edwards (2017) and Timm et al. (2014).

\subsection{Conductivity in active subduction zones: Case studies}

The remote detection of fluids in the crust and mantle is possible by integrating independent geophysical tools, such as seismics and MT methods. In this chapter we review some casestudies from the Andes, Cascadia, and Puerto Rico subduction zones. Based on the observations by Shmulovich et al. (2001), Kawamoto et al. (2012, 2013), and Manning (2004), it is evident that proper interpretation of conductivity measurements in the mantle, requires input from thermodynamics and knowledge of mineral processes in water-wet, supercritical, and subcritical systems. The partitioning of conductive minerals and salts in the two fluid systems and their possible interaction with minerals in the lower crust, is also of importance for the interpretation.

\subsubsection{The Altiplano, Uyuni}

The Altiplano of the Chilean and Bolivian Andes have been studied extensively by several authors, Bedrosian (2007), Brasse et al. (2002), Schwalenberg et al. (2002), Schilling et al. (2006), Kühn et al. (2014) and Araya Vargas et al. (2019). Seismic data are combined with MT data between the Pacific ocean and the Altiplano region, between ca $20^{\circ} \mathrm{S}$ and $21^{\circ} \mathrm{S}$. (Fig. 8).

Figure 8. Magneto-telluric (MT) networks in the Altiplano area, (Modified from Brasse et al. (2002)). The red rectangle shows the location of Fig. 10.

One MT network is named ANCORP, where sensors are placed along the southern banks of the largest salt lake on Earth, Lake Uyuni (Fig. 8). Another, network, (PICA) is located further north and extends to the northwestern corner of Lake Uyuni. The Altiplano region is situated above a section with low angle subduction by the Nasca plate. The investigations clearly indicate the presence of major conductive zones below the Lake Uyuni area. A zone of diverging seismic velocities (ALVZ) is observed on top of the large conductor. The upper part of the conductive region is situated below ca. $20 \mathrm{~km}$ depth and temperatures around $500^{\circ} \mathrm{C}$. See Fig. 9.

Figure 9. Measured electric conductivity below the Altiplano along the ANCORP network. Warm colours indicate zones of high electric conductivity (Low resistivity). Seismic activity is indicated by black dots (Earthquakes). The zone of diverging seismic velocity (ALVZ) is indicated by white, dotted lines. (Modified from Brasse et al. (2002)). 
Brasse et al. (2002) concluded: «This highly conductive domain also coincides with low seismic velocities and a zone of an elevated $v p / v s$ ratio and, although not well resolved, with low Qp seismic quality factors. Taking into account the enhanced heat flow and a derived temperature model, the most probable explanation lies in the assumption of granitic partial melts».

The observation of an anomalous heat-flow of up to $40 \mathrm{~mW} / \mathrm{m}^{2}$ more than the expected value, is not consistent with available radioactive elements in the area. Simulations on melt fractions and melt configurations have not been successful in recreating the appearance of the conductive zone. Although partial melts might explain the observations at depth and at elevated temperatures, low temperatures at ca. $20 \mathrm{~km}$ depth are not consistent with extensive melting. Schilling et al. (2006) point at the petrological evidence for high oxygen fugacity in ignimbrites in the area. This would argue against reduced carbon or graphite, in the crust, as being the cause for enhanced conductivity. Furthermore, graphite alone, or any other conductive minerals such as ores, would not cause the reduction in seismic velocities and damping of seismic waves as observed.

Some of the enigmatic observations of the ALVZ-reflector was summarized by Kühn et al. (2014): "It remains enigmatic, however, why seismology sees the top of the fluid accumulation zone significantly lower than our MT model». Seismology is sensitive to pore pressures and fluid content of the rocks, whereas elevated conductivity can also be the result of mineral type and fluids. The combination of depth, seismic activity, high $\mathrm{Vp} / \mathrm{Vs}$ ratios and temperature/heat production, indicates that invasion of high pressure fluids from below and the presence of certain minerals might be the cause.

Pictures, obtained from Google Earth, shows that Lake Uyuni has numerous springs/pockmarks on the surface, thus indicating possible flow of saline fluids from the mantle, all the way to the surface (Fig.10).

Figure 10. Section of Lake Uyuni, Bolivia, showing numerous pockmark-like, saline springs on the surface. (Google Earth). Image a) is an image from an elevation of $13,370 \mathrm{~m}$ above the salina. Image b) shows a smaller area of this location obliquely from an elevation of $3,863 \mathrm{~m}$ abrove ground. The circular and semi-circular features have no significant elevation above the lake floor, but must be caused by point-source seepage of fluids. (For location, see Fig. 8. Image obtained from Google Earth, 2021).

One surprising observation by Kühn et al. (2014) is the lack of conductivity directly below the volcanic arc. Similar observations are made in many other volcanic systems. Because volcanoes are driven by water, this tells us something about the non-conducting properties of some water-rich melts. A possible explanation for this phenomenon is presented by Samrock et al. (2021) where conductivity is claimed to be caused by three factors; melt conductivity, solids conductivity, and conductivity in a melt volatile phase (MVP) (Kawamoto et al., 2012). Samrock et al. (2021) claim that the more silicic melts are more conductive and that the types of dissolved minerals in the MVP is important for the total conductivity. Na-ions are regarded 
as important current carriers and their ability to move freely in the melt/fluid/rock-system is important for the observed conductivity. According to Samrock et al. (2021), adding $1 \mathrm{wt} \%$ of dissolved $\mathrm{H}_{2} \mathrm{O}$ to a melt, leads to a 1.3 to 2.5 -fold increase of the melt's electrical conductivity. The implication of this is increasing conductivity with increased content of minerals incorporating sodium and silica in volcanic melts.

\subsubsection{Altiplano-Puna}

Above the Altiplano-Puna Magma Body (APMB), near the Uturuncu volcano, Laumonier et al. (2017) measured the electrical conductivity at depth. They also studied the Southern Washington Cascades Conductor (SWCC), using MT methods. Their objective was to estimate the apparent water content in these volcanic systems. Their estimates of water content in APMB and SWCC were based on calibrations from crystal-liquid equilibria and rock melt $-\mathrm{H}_{2} \mathrm{O}$ solubility experiments. Based on measurements of conductivity, laboratory experiments on the observed mineralogy and calculations with varying degrees of melt fraction and water content, their conclusion on the conditions within the APMB was as follows: «These independent constraints strongly indicate that the magma body at 15 to 30 $\mathrm{km}$ bsl contains 10-20 vol\% of $\mathrm{H}_{2} \mathrm{O}\left({ }_{(} \mathrm{CO}_{2}\right)$-saturated andesitic melts at a temperature close to $980^{\circ} \mathrm{C}$ within a solid matrix.» And: «The minimum melt water content must be 8 wt $\%$ in order to have Ca-rich plagioclase on the liquidus and to be sufficiently conductive.» Laumonier et al. (2017) estimated the total volume of this water-rich magma body, to be $500000 \mathrm{~km}^{3}$.

Obviously, other substances might contribute to the observed conductivity, for instance salts. Salts, if present, would reduce the estimated water content and still produce the observed conductivity. Laumonier et al. (2017) discuss this possibility: «Saline fluids could generate the high conductivity of the APMB if they could connect over large distances (several 10s of $\mathrm{km}$ ), though the geological process producing such a large amount of chlorine-rich fluid is unclear. Exsolution of magmatic volatiles from magma would produce high temperature, water-rich and chlorine-poor fluids, remaining as bubbles in the magma and therefore invisible to MT data.»

In our opinion, subducted salts might be contributing to the observed conductivity. In addition, saline fluids create interconnected pores in magmatic systems.

As a result of a mass balance calculation on the amount of subducted water in the region, Laumonier et al. (2017) concluded that their estimate for water content within this subduction zone was unusually high compared to an average subduction zone. This might also be an indication that less water and more salts are involved.

Data collected from the MT network in APMB are reported in more detail by Comeau et al. (2015). Clear indications of conductivity below $20 \mathrm{~km}$ depth (below sea level) were observed, with diapiric sections from this level up to ca. $5 \mathrm{~km}$ depth. Comeau et al. (2015) interpret the conductive zones beneath the volcanic center to be andesitic melts. This is also in accordance with observations by Samrock et al. (2021) for andesitic melts with salinity and high silica content. 
Other shallow, high conductivity zones are interpreted as partial melts or fluids, by Comeau et al. (2015). Fig. 11 shows parts of the Uturuncu region, above the APMB. The image clearly shows salt lakes and large pockmark fields, indicating the escape of saline- and perhaps less saline fluids, from subsurface sources.

Figure 11. Image from the Uturuncu area above the APMB (Altiplano Puna Magma Body). Salt lakes are observed at 7-10 km distance to the east- and south of the volcanic centre. Pockmarks, indicating fluid flow from below, are observed in the image (upper centre). The border between Bolivia and Argentina is shown in the lower right corner (Image obtained from Google Earth 2021).

Weis (2015) has performed numerical simulations of fluid behaviour in volcanic porphyry copper systems. The simulations include variation of brittle/ductile properties and permeability, hydraulic fracturing and different salinities. Weis (2015) presents results from simulating a volcanic topography with influx of meteoric, colder water and a self organizing permeability development in the mixing zone between magmatic and meteoric fluids in a zone around the magma chamber. In this situation, the expelled fluids from crystallizing magma would follow a path to the surface, up to $7 \mathrm{~km}$ away from the volcanic center, which is analogous to observations around the Uturuncu volcano. An illustration of this is shown in Fig. 12.

Figure 12. Simulation of the saline fluid system around a volcanic magma chamber after 30000 years. Hot saline fluids are directed sideways by precipitating solids in the flow path, due to mixing with colder meteoric water from above. Modified from Weis (2014).

Observations of high conductivity around volcanic centra, rather than directly below, might therefore be an indication of saline fluids forced into following the path of highest permeability after being expelled from crystallizing, outer parts of a magma chamber.

\subsubsection{Cascadia subduction zone}

Wannamaker et al. (2014) presents results from the Western US, including the Southern Washington Cascades Conductor (SWCC). They identify low-restivity zones at slab depths of $35-40 \mathrm{~km}$ starting ca $100 \mathrm{~km}$ west of the volcanic arc in all conductivity profiles along the western US (Figs. 13 and 14). This is interpreted as being a result of prograde metamorphic fluid release from the subducting slab as a result of eclogitization at estimated temperatures of $500-550^{\circ} \mathrm{C}$. The fluids rise to Moho levels and even crustal level not far from the arc and are thought to have broken through the brittle crustal domain in a fracture mesh. Since this apparent fluid release is in close proximity to where low frequency earthquakes are located, a connection between the two is likely. Wannamaker et al. (2014) also discuss the role of salinity in the observed conductive zones. A saline fluid content as low as $0.2 \%$ might produce the observed response, although it is not believed that the subducting slab would release saline fluids, the salinity might possibly increase during ascent in the mantle wedge. 
The ascending fluid is believed by Wannamaker et al. (2014), to be responsible for extensive serpentinization of the upper mantle wedge.

In the deeper segments, within the mantle wedge, a large and deep zone of increased conductivity is observed. This is interpreted by Wannamaker et al. (2014) to be due to chlorite mineral breakdown and fluid release down to $800^{\circ} \mathrm{C}$. This zone is assumed to represent flux melting and it ascends nearly vertically towards the surface where it combines with the conductive zone arising from eclogitization, just in front of the volcanic arc. As shown earlier, this assumption is not valid. Huang et al. (2019) state that depleted peridotite solidus is at $1050^{\circ} \mathrm{C}$, implying that fluids rather than melts were observed.

McGary et al. (2014) used seismic information to constrain the magneto-telluric inversion, from the SWCC. A clearer impression of the conductive zones emerges (Fig.13 and Fig.14).

Figure 13. Conductive zones around the Cascadia subduction zone near Mount Rainier. Warm coulors indicate high conductivity. Conductive fluids and melts are seen rising from above the cold, non-conducting, subducting, slab. Observed earthquakes around $20 \mathrm{~km}$ depth is indicated by black circles. Mount Rainier volcano is indicated with a red triangle.

(Modified from McGary et al. (2014)).

Figure 14. Seismic image from the Cascadia region. Horizontal distance from the US east coast is shown. Blue colors represent fast propagating seismic waves and red colours represent slower propagating waves. Earthquake regions are indicated with black circles. A zone of lower seismic velocity can be seen above the zone where the earthquakes are located. Mount Rainier volcano is indicated with a red triangle. Modified from McGary PhD Thesis (2013).

A conductive zone is shown above the subducting slab, from $120 \mathrm{~km}$ depth and nearly to the surface some kilometres away from the volcanic center at Mount Rainier. The supposed, near horizontal shear zone identified by Wannamaker et al. (2014), is more prominent in the results presented by McGary et al (2014). McGary et al. (2014) identify this seismogenic zone below $20 \mathrm{~km}$ depth, as being associated with fluids from the dehydration of hydrated metabasalt in the upper-crustal layer of the descending slab. Earthquakes are observed along the path of fluids moving from this dehydration zone. They are seemingly all located at ca. $20 \mathrm{~km}$ depth and a bit below the upper limit of the conductive zone. A temperature of $400{ }^{\circ} \mathrm{C}$ to $500^{\circ} \mathrm{C}$, at $20 \mathrm{~km}$ to $30 \mathrm{~km}$ depth, is too low to induce melting. A depth of $20-30 \mathrm{~km}$ would likely be within the ductile section of the lower crust.

The combination of hydration, distinct seismicity and location of the conductive zone, resembles the situation observed by Kühn et al. (2014) in the Altiplano. Earthquakes might be the result of movement along a shear zone at ca. $20 \mathrm{~km}$ depth, as suggested by Wannamaker et al. (2014). Similar to the observation by Kühn et al. (2014) in the Altiplano, the pertubation in seismic velocity from high to low, is also observed by McGary et al. (2014). The localizing 
of earthquakes by McGary et al. (2014) at- and below $20 \mathrm{~km}$ depth, but not above, might also indicate presence of strain hardening minerals, capable of brittle behaviour even at this depth. Strain hardening of certain minerals is discussed futher in Ch. 6.1.

Moho is located by McGary et al. (2014) at ca. $40 \mathrm{~km}$ depth. Low conductivity is observed below the Mount Rainier volcano. Nevertheless, a combination of low conductivity and low seismic velocity at depth, to the east of the volcanic centre, might still indicate less conductive melts.

\subsubsection{Costa Rican subduction zone}

MT studies on the Costa Rican subduction zone, have been published by Worzewski et al. (2010). An important finding is the observation of deep influx of water as the slab bends downward into the subduction zone. Their data reveal that bending-related faulting of the incoming plate permits water penetration down to at least $20 \mathrm{~km}$ depth and, thus, promoting serpentinization and transport of substantial amounts of water and salts deep into the subduction zone.

One of their main findings comparing nine different subduction zones, was the consistent positioning of an upper conductive zone from $20 \mathrm{~km}$ depth and downwards, in front of the volcanic arc. They also observed a common value of 20-40 km distance between the conductive zone and the volcanic arc. A conductive region, above the zone of eclogitization, is observed.

Both Wannamaker et al. (2014), McGary et al. (2014) and Worzewski et al. (2010) observe that the zone directly below the volcanic arc has a significantly lower conductivity than the zone ca. $30 \mathrm{~km}$ away from the arc. This is probably indicative of the type of magma and also an indication that the conductive zone away from the arc, might be caused by a colder, more conductive fluid system, separate from the fluids causing the less conductive magmas beneath the volcanoes.

Worzewski et al. (2010) observe a conductive fluid expulsion from the slab at 12-15 km depth where fluids have been found to leak all the way to the seabed through deep seated faults. This is consistent with observations from Wannamaker et al. (2014), Bonner (2015) and others. This fluid expulsion is believed to be caused by clay mineral breakdown in sediments on top of the slab. According to general observations by Samrock et al. (2021), smectites at the near surface level might also explain this high conductivity zone, and even more so, if the smectite has been invaded by saline fluids.

Hensen et al. (2004) examined fluid content in shallow sediment cores taken from submerged mud mounds along the Costa Rican coast. The fluids were generally less saline than seawater and isotopic analysis to determine temperature at clay mineral dehydration within the slab, gave an interval between 80 and $130^{\circ} \mathrm{C}$. The ultimate source of water in these sediments is seawater with substantially higher salinity than the expelled water. Some of the salts brought in with this seawater, must, therefore, be stored somewhere in the accretionary wedge, be leaking out undetected by Hensen et al. (2004), or transported further into the subduction zone. 
This indicates that saline fluids might be the cause of the observed, deeper conductivity zone.

\subsubsection{Additional cases}

Bedrosian (2007) presents results from some case studies. One particularly interesting study was made along the San Andreas fault in California. Using continuous MT profiling, a flower structure was identified within the upper 1-3 km of the San Andreas Fault. The enhanced conductivity within the fault zone was attributed to saline fluids. Using salinity estimates from a nearby well, a range of subsurface porosities was further estimated consistent with the imaged conductivity, using Archie's Law. The combination of tomographically-derived velocity models and regional seismicity revealed a spatial separation between the highconductivity, low velocity fault zone and microseismicity. This was interpreted to be caused by fluid-filled fractures, giving rise to the high conductivity and low velocities, while preventing buildup of shear stress necessary for brittle failure, thus limiting earthquakes to the boundaries of this region. The combination of conductive crustal zones near,- but not within, regions of high seismic activity, is frequently observed as reported by Bedrosian (2007). Such observations are clear indicators of conductive fluids and hydraulic fracturing and not melts or conducting graphite.

In a study by Park and Ostos (2013), collecting data from a MT network from the California Great Valley to the border of Nevada, salinity seems to provide the explanation of the observed conductivity. Park and Ostos (2013) concluded that the zone of high conductivity above the subducting slab at $100 \mathrm{~km}$ depth, must be caused by saline fluids. Several zones of high conductivity above this zone were also observed at depths between 15 and $30 \mathrm{~km}$, and believed to be basaltic mantle reservoirs heating and melting the crust. Saline fluids within the ductile section of the crust were, however, not considered.

Heise et al. (2012 and 2017), report from a MT study on the Hikurangi subduction zone on the northern island of New Zealand. One of their findings was a trench-parallel conductive layer above the subducting slab at $25-30 \mathrm{~km}$ depth, seemingly connected to a similar conductive layer at between 12-15 km depth, via a conductive "channel" through a non-conducting zone. The non-conducting zone shows higher seismicity than the rest of the area.

On the cause for the observed conductivity, Heise et al. (2012) state: "Given the low temperature of the subducted plate and the low $V_{p}$ values, the most plausible cause of the low resistivity is the presence of aqueous fluids within a zone of under-plated sediment.

Supporting this interpretation are the high $V_{p} / V_{s}$ values seen in the seismic tomography which are indicative of over-pressured fluids». Heise et al. (2017) interpret the conductivity to be due to fluid- and clay-rich sediments, whereas the non-conducting zone is understood to have less sediments and fluids.

In our view, their observations and data confirm the expulsion of saline, high-pressure fluids from the subducting slab.

Davey and Ristau (2011) have performed seismic investigations and mapping of seismicity in the northern part of New Zealand, in the region also examined by Heise et al. (2012). They identified three seismic active clusters above the subducting slab, each approximately $12 \mathrm{~km}$ 
in diameter from a depth of $55 \mathrm{~km}$ up to $35 \mathrm{~km}$. The clusters correspond closely with a change from low to high $\mathrm{Vp}$ and $\mathrm{Qp}$, and with an average $\mathrm{Vp} / \mathrm{Vs}$ ratio that is interpreted to be caused by the dehydration af the serpentinised slab. The location and spacing of the clusters were found to be consistent with thermally driven diapiric- or fluid upwellings and also a spatial relationship with proposed lithospheric fractures and associated volcanic seamounts on the subducting Hikurangi plateau. This further confirms expulsion of saline, high-pressure fluids from the subducting slab in the Hikurangi subduction zone.

Nakajima et al (2001) have produced a 3D structure of Japanese subduction zones based on pertubations in the seismic velocities of pressure waves, Vp and shear waves, Vs. Based on their measurements they suggest that partial melts rise from the subducting slabs and that the partial melting zones under northeastern Japan spread out from the uppermost mantle along the volcanic front up to the midcrust immediately beneath active volcanoes. The low- $\mathrm{Vp}$, low$\mathrm{Vs}$, and low $\mathrm{Vp} / \mathrm{Vs}$ features in the upper crust seem to indicate the presence of $\mathrm{H}_{2} \mathrm{O}$, rather than melt beneath the active volcanoes. Earthquake swarms were located below $20 \mathrm{~km}$ depth in parts of the crust where Vp/Vs is moderately low. Nakajima et al. (2001) interpret the earthquake swarms in those areas to be caused by the $\mathrm{H}_{2} \mathrm{O}$ expelled from a solidified partial melting material, indicating expulsion of fluids. The methods used by Nakajima et al. (2001) are not suited for definitive differentiation between fluids and melts. Some of the interpreted melts and magmatic processes might, therefore, instead be interpreted as saline fluids and sub solidus mineral reactions.

The observation of earthquake activity below $20 \mathrm{~km}$ depth is analogous to the observations from the CWCC (McGary et al. (2014), Wannamaker et al. (2014)), indicative of a mineral system capable of strain embrittlement at depths where ductility and lack of earthquakes is the norm.

Booker et al. (2004) performed a MT study in the Sierras Pampaneanas of Argentina. Their results indicate fluid release above the steepening part of a flat Nasca slab. High conductivity is also indicated in the near surface, above the steep slab, where several saline lakes are located at ca. 65 degrees west and ca. 30 degrees south. This is consistent with observations by Gutcher et al. (2000) from the same area. They also confirm the presence of a deep shear zone above the steepening part of the slab.

\subsection{Conductivity of intracratonic crust and mantle}

All continents are the result of tectonic processes involving subduction, in periods. One should, therefore, expect to find inherited structures from such events in the crust and mantle of stable continents. Of special interest to this study, would be observations indicating salinity still existing in the mantle and crust, from fossil subduction zones.

The continental crust and mantle of the Himalayan orogeny have been investigated in several studies utilizing a number of indepentent MT networks. A few results will be mentioned here to illustrate that even for this area, with very thick crust (50-70 km in places), the observation of conductive zones show what seems to be the result of a common, general process located above Moho, in the lower crust. 
Wei et al. (2006) performed a MT study of the northern Tibetan Plateau. Several, large and independent conductive zones are observed in between less conductive zones, all along the magneto-telluric network. The more prominent conductive zones are all located beneath depths ranging from $20 \mathrm{~km}$ down to $30 \mathrm{~km}$. Several smaller conductive zones rise higher than $10 \mathrm{~km}$, and some seem to go all the way to the surface. Among the larger conductive zones, some go very deep. Zones of high conductivity are found in connection with well known suture zones. Based on conductivity measurements alone, this association might be due to weaknesses created by fluids, or vice versa. Some conductive zones continue down to the depth limit of the investigation $(100 \mathrm{~km})$.

Wei et al. (2006) concluded that a: «... pervasively high conductance suggests that partial melt and/or aqueous fluids are widespread within the Tibetan crust. In southern Tibet, the high-conductivity layer is at a depth of 15 to 20 kilometers and is probably due to partial melt and aqueous fluids in the crust. In northern Tibet, the conductive layer is at 30 to 40 kilometers and is due to partial melting. Zones of fluid may represent weaker areas that could accommodate deformation and lower crustal flow».

It is not self-evident that melts exist at $20 \mathrm{~km}$ depth, as the temperatures at this depth, normally, do not exceed 5-600 ${ }^{\circ} \mathrm{C}$.

Zhang et al. (2013) report results from an $800 \mathrm{~km}$ long MT network in a different region of the eastern Tibetan Plateau. Conductive zones are detected between $20 \mathrm{~km}$ and $30 \mathrm{~km}$ depth. Data indicate a physical link between other conductive zones and deep faults reaching well beyond Moho depth. A large-scale conductor is located below $20 \mathrm{~km}$ depth in the lower crust beneath the Songpan-Ganze Block. According to Zhang et al. (2013), it might act as a guiding channel that facilitates the eastward escaping movement of crustal materials from the Tibetan Plateau.

This observation strongly indicates that the zone below $20 \mathrm{~km}$ depth has a fault-localising capability.

Li et al. (2020) collected MT data to obtain a continuous image of the lithospheric electrical conductivity across the southeastern Tibetan Plateau margin. The resulting resistivity model reveals two major conductive features in the middle-lower crust beneath southeastern Tibet and the Chuxiong basin, both of which are consistent with the presence of fluids and likely enhanced by shear deformation along large faults. An anomalously high conductive zone was observed beneath the Chuxiong basin and was interpreted to contain substantial amounts of saline aqueous fluids.

As presented above, in studies performed on the Tibetan plateau, associations between faulting, suture zones, and zones of high conductivity are common. In a study of a fossil (Neoproterozoic to the end Paleozoic) intraoceanic subduction- and accretion zone in China, $\mathrm{Xu}$ et al. (2016) made several important observations related to this subject. Data from conductivity measurements along a MT network show the presence of solute-rich fluids above the fossil subduction zone (Fig. 15). 
Figure 15. MT image of the fossil subduction zone (Neoproterozoic to the end Paleozoic) in western Junggar, China. Solute rich fluids are observed at ca. $20 \mathrm{~km}$ depth around deep fault zones. Regions with confirmed serpentinisation at/near the surface, have low conductivity. Modified from Xu et al. (2016).

Surprisingly, serpentinites observed in the area by Xu et al. (2016), (Fig. 15), show up as nonconducting, although several studies have shown that serpentinsation by saline fluids, produce serpentinites that contain substantial amounts of salts, eg. Huang et al. (2018), Scribano et al. (2017). Commonly, the measured conductivity of serpentinised, subducting slabs, is also often low. This subject is further discussed in Ch. 6.2.

The 3D MT conductivity models established by Hill et al. (2021) of the Archean Superior Province in Canada, reveal the presence of high conductivty zones in the mid - lower crust. These were interpreted to reflect a protracted history of magmatic-hydrothermal activity contemporaneous with construction and collapse of the crust. Sub-vertical zones of high conductivity in the mid - upper crust, are inferred to represent corridors of paleo-fluid flow along crustal-scale structural networks and faults developed in response to terrane amalgamations. Subsequent orogenic collapse resulted in widespread lateral flow within the lower crust, accommodated by sub-horizontal shear zones, and included magmatic refertilisation. Fig. 16 shows conductivity measurements in the Malartic region of the Abitibi subprovince, in Eastern Canada.

Figure 16. Conductivity measurements in ca. $2.7 \mathrm{Ga}$ old craton in the Superior Province of eastern Canada. The depicted section is located in the Malartic region of the Abitibi subprovince. Deep crustal conductivity is observed in zones below $20 \mathrm{~km}$ depth. Subvertical, conductive zones extend all the way to the surface, along major fault zones. LCC- Lower Crustal Conductive zone. VC4, VC5 and VC6 indicate sub-vertical conductive zones. (Modified from Hill et al. ( 2021)).

Hill et al. (2021) conclude that the preserved high-conductivity anomalies in the mid-lower crust represent an amalgamation of magmatic-hydrothermal and deformational processes that occurred during construction, peak orogenesis, and collapse in the Archean. Conductive zones, extending all the way to the surface, might possibly be caused by brines similar to those sampled from the Canadian shield in a mineral assemblage consisting of chlorite, amphibole, albitized plagioclase, and minor epidote, by Bottomley et al. (2005).

Thus, it seems that even in very old cratons, conductive patterns emerge, similar to those observed in regions with ongoing subduction. The presence of similar conductive zones below ca $20 \mathrm{~km}$ depth in archean, eroded crusts, as well as in newly formed crust, seems to indicate that the same metamorphic processes are maintained at these depths as long as there is fluid supply from the mantle.

Based on data, using different methods in different tectonic settings, a set of common observations emerge: 
- Similar conductive patterns emerge in regions with ongoing subduction, and within old cratons.

- Subduction zones and old cratons show evidence of conductivity created by saline fluids, also in zones where temperature does not allow melting.

- Saline fluids ascend from subducting slabs, through the mantle wedge, towards a trench parallel zone ca. $30 \mathrm{~km}$ from the volcanic arc, in the direction of the subduction trench.

- Saline fluids remain in the mantle and lower crust, although some fluids may invade the upper crust via deep faults and weakness zones.

- Trench parallel zones of conductivity, showing anomalous seismic velocities, ductilebrittle behaviour, and seismicity, are located at ca. $20 \mathrm{~km}$ depth and below, indicating certain mineralogical- and mechanical properties of this zone, also related to fluids.

\section{Rifting of continental crust and mantle}

\subsection{Lower crust vs. Lower Crustal Body, 'LCB'}

As presented above, parts of the lower crust that has been subjected to ascending fluids from subduction zones, has distinct properties that have been observed and debated for many years (Hyndman and Shearer (1989)). Seismicity in such regions is commonly observed at depths of $20 \mathrm{~km}$ and below (McGary et al. 2014). As shown earlier, conductive zones may extend from this level to slightly higher elevation along localised channels.

The lower crust also plays an important role in the rifting process. Modeling of existing rifts appears to require brittle deformation of an initially strong and gradually weakening lower crust, to produce the observed rift development and geometry (Gueydan et al. (2014), Allen (2016), Brune et al. (2017) and Manatchal et al. (2015)). However, the modellers are facing the enigmatic fact that the intraplate continent remains strong and unaffected, while the rifting section seems to become weaker and weaker during the rifting phase. In addition, there is the problem of explaining why the rifting starts where it does. In numerical models, this weakness is introduced by the modeler. In nature, unobserved factors that apparently are destroyed by the rifting process, itself, may play a role.

Thus, the understanding of inherited properties is of prime importance when modelling the localisation and evolution of rifts. Manatschal et al. (2015) studied the influence of structural-, compositional-, and thermal inheritance. They state that there is general agreement that inheritance ought to have an important influence on the architecture and tectonic evolution of rifted margins. However, it is not yet clear how inheritance controls the initiation and evolution of rifting and lithospheric breakup. Reactivation of pre-existing faults is an obvious candidate, as well as major lithological boundaries. Nevertheless, early stages of rifting are often diffuse and these features do not, in most cases, coincide with the location of the final breakup. 
Thermal inheritance alone, is not the most obvious candidate because inherited heat will dissipate over time.

The composition of the crust is in most cases rather complex and often covered by volcanics or sediments in the regions holding the answers to the questions of compositional inheritance. Manatschal et al. (2015) concluded: «Mantle composition and mantle processes occurring before and during rifting may control the rheology of the mantle, the magmatic budget, the thermal structure and the localisation of deformation during late stages of continental crust attenuation and lithospheric breakup, while early stages are rather controlled by upper crustal inherited structures».

In a study from offshore mid Norway on continental margin formation (rifting), an underplated structure was closely examined and modelled by Rupke et al. (2013). A parameter study shows that a critical stretching factor exists for which complete crustal embrittlement and assumed serpentinisation occurs. Predicted thicknesses and locations of partially serpentinised mantle rocks were found to be consistent with seismic- and gravity data. The conclusion by Rupke et al. (2013) was that a zone at ca. $20 \mathrm{~km}$ to $30 \mathrm{~km}$ depth along the investigated part of the Norwegian margin, might consist of a partially, serpentinised mantle. Their extension model and timing were found to fit with a minimum amount of sediments in combination with serpentinisation of the rifted LCB, from above.

Petersen and Schiffer (2016) studied and modelled seven transects within the rifted margin of the north Atlantic Ocean, between northern Norway and Spain. In all seven transects, a LCB was observed below ca. $20 \mathrm{~km}$ depth. The LCB was interpreted as being serpentinised mantle. In all seven transects, the LCB was split into two parts by later rifting, indicating some common localising feature.

Petersen and Schiffer (2016) concluded that structures inherited from previous orogenic events in the crust and the underlying lithospheric mantle, might be the cause for mechanically weak zones that were crucial for rift localisation.

Among the important conclusions made by Petersen and Schiffer (2016) are the following:

1. «It is mechanically feasible that passive margin formation and evolution can be controlled by the presence of pre-existing orogenic structures.»

2. «Serpentinite, often forming the crystalline basement of distal zones of magma-poor margins, can be explained by exhumation of fossil mantle wedge material formed during pre-rift subduction of oceanic crust.»

3. "Similarly, fossil mantle wedge material can also become emplaced at the base of thinned continental crust and form LCBs with typically higher than crustal, but lower than mantle velocities.»

4. «Fossil slab material entrained in the lithospheric mantle at the onset of extension is rheologically similar to the hosting mantle lithosphere and does not cause intense strain localisation upon extension. It may therefore 'survive' extension and either break passively apart to form two dipping structures in the mantle lithosphere of each 
conjugate margin, or it may become sheared along the Moho on the side of the rift where the slab was shallowest»

Based on the work presented above, it seems evident that conductive zones in lower crust and mantle, influenced by saline fluid flow from below, play an important role during rifting, and that the conductive zones observed below $20 \mathrm{~km}$ depth above subduction zones and within cratons, represent what is often referred to as Lower Crustal Bodies (LCBs).

\subsection{Constraining the properties of the LCB}

Belusov (1966) give a description of the different zones of the upper mantle and crust. He describes the the section around $20 \mathrm{~km}$ depth as being composed by amphibolite- and granulite facies rocks. This section of the lower crust is also penetrated by diapiric intrusions created by astenospheric upwelling. This view is also shared by Touret (2009). He concludes that the granulites observed in Norway and elsewhere were exposed to massive amounts of saline fluids transferred from the mantle into the crust by synmetamorphic intrusives.

As seen from the reported work on LCBs above, serpentinites often represent the suspected mineralogy of the LCBs due to suitable conditions in pressure and temperature at the observation depth. However, serpentinites alone are not satisfying all of the observed properties of LCBs, as serpentinites are not found to be particularly conductive.

Huang et al. (2018) has documented the presence of structurally bound chlorine in serpentine without close association with sodium. Without a free fluid phase within serpentinites, this would tend to reduce the conductivity of serpentinites. We, therefore, postulate that the interpretation of serpentinites as the only rock types in LCBs represent an oversimplification, and that other rock types must also be involved to explain all observations.

The observation of seismicity in combination with conductivity at slightly different depths, is also signalling that, serpentinites might not be the only candidate. As observed by Hess (1933), serpentinites forming from already water-containing peridotites, will not be accompanied by volume expansion, and therefore not likely to produce seismicity during the serpentinisation process.

With respect to the observed brittle behaviour of LCBs during rifting, serpentinites have been shown to produce the observed strain embrittlement when stressed at relevant pressures and temperatures. In a study by French (2019), laboratory tests were made to determine the shear strength of antigorite under high temperature, pressurised conditions. Additions of water was also included. Measurements were performed at $500^{\circ} \mathrm{C}$, and pressures above $1 \mathrm{GPa}$. At all fluid conditions, the serpentinite was found to exhibit strain hardening and brittle fracturing during distributed deformation, but also minor strain weakening associated with the formation of prominent shear fracture zones. Thermal stability of antigorite is approximately $600-650$ ${ }^{\circ} \mathrm{C}$. However, antigorite was shown to dehydrate locally even at $500{ }^{\circ} \mathrm{C}$ where it is normally stable. The deformation proved to be brittle, with the development of numerous cracks. 
Adding water, reduced the strength of antigorite but the deformation mechanism remained frictional. Antigorite may therefore initially be a soft mineral, that hardens with strain and maintains a brittle behaviour during rifting. Antigorite might also release water and produce olivine during deserpentinisation caused by frictional heat, or heat from other sources. As observed by Engvik et al. (2018), other mineral systems in the lower crust, involving scapolite metagabbro and scapolite-bearing amphibolites might also show brittle/ductile behaviour.

Soret et al. (2019) studied the deformation mechanisms in mafic amphibolites and granulites at relevant temperatures and pressures. They documented that garnet-clinopyroxene amphibolites accommodate large shear strain essentially through fracturing, grain size reduction and grain boundary sliding, confirming that also amphibole and amphibolite will behave in a similar manner as antigorite, with strain hardening, fluid release, and subsequent weakening when subjected to shear stress.

These results show that relevant sections of the lower crust might deform by brittle deformation, given the right mineralogy, even when pressure and temperature indicate ductile behaviour.

However, the challenge of satisfying the observed conductivity at lower crustal levels, still remains.

Yang et al. (2011) have measured the conductivity of lower crustal clinopyroxene at 6 - 12 kbar, $250{ }^{\circ} \mathrm{C}-1000{ }^{\circ} \mathrm{C}$ and a water content of $0-375 \mathrm{ppm}$. Clinopyroxene is considered to be a very common mineral at lower crustal conditions. Dry clinopyroxene was found to be conductive from hopping of electron holes due to the content of $\mathrm{Fe}^{2+}$ and $\mathrm{Fe}^{3+}$ of the mineral. The wet samples were found to be conductive due to charges carried by protons. Conductivity was found to increase linearly with water content. During all tests the oxygen fugacity was kept at the Ni-NiO buffer conditions.

Wang et al. (2011) have performed conductivity measurements on amphibole-bearing rocks at conditions of the middle- to lower crust. The starting materials, during their tests were natural plagioclase-hornblendite and hornblendite. The electrical conductivity of the rocks were found to be weakly temperature dependent below ca. $800 \mathrm{~K}\left(\mathrm{ca} .530^{\circ} \mathrm{C}\right)$ and relatively low conductivity (ca. 5 e $10^{-3} \mathrm{~S} / \mathrm{m}$ at ca. $750 \mathrm{~K}\left(\mathrm{ca} .480^{\circ} \mathrm{C}\right.$ ). The electrical conductivity was observed to increase rapidly above ca. $800 \mathrm{~K}$ (ca. $530^{\circ} \mathrm{C}$ ). Infrared spectroscopy observations indicated that dehydration occurs in this high temperature regime. Wang et al. (2011) concluded that the increase in conductivity is not due to the direct effect caused by the generation of conductive fluids. Rather, it was concluded that dehydration of amphibole is associated with the oxidation of iron (from ferrous to ferric). Thus, they suggest that the increased conductivity associated with dehydration is caused by oxidation. The dehydration mechanism involved was found to produce hydrogen and not water. 
According to Kozlovsky (1987), large amounts of hydrogen were encountered at depth in the deep Kola well, as well as brines and large sections of amphibole rocks. Thus, it is very likely that this type of reaction might be involved in producing both the observed seismic- and conductivity response, at lower crustal levels.

Another reaction that might produce conductivity at lower crustal levels, involves albite, quartz, water and $\mathrm{NaCl}$. This system has been studied by Guo et al. (2015) at temperatures between $400 \mathrm{~K}$ and $1000 \mathrm{~K}$, at a pressure of $1 \mathrm{GPa}(10 \mathrm{kbar})$. The electrical conductivity of the albite-quartz-water samples was found to decrease with decreasing temperature from $1000 \mathrm{~K}$ to $800 \mathrm{~K}$, then increased rapidly upon further cooling from $800 \mathrm{~K}$ to ca. $550 \mathrm{~K}$. Adding $\mathrm{NaCl}$ to the system produced a higher conductivity, increasing with salinity and water content. Guo et al. (2011) conclude that the observed conductivity in the lower crust could be explained by a brine-bearing albite with a fluid fraction of 1 vol\% seawater at temperatures lower than $380{ }^{\circ} \mathrm{C}$

In the typical lower crustal level above a subduction zone, the crust would be invaded by hot fluids from below and any mineral reactions involving water and salts would start out hot and become cooler at higher levels. The conversion from a hot, wet peridotitic mantle and the lower crustal minerals initially would involve mineral grains and pore waters with dissolved minerals/salts. When allowed, by lower temperature/pressure, minerals will gradually hydrate and form new minerals. Clinopyroxenes in the upper mantle/lower crust, would therefore, not be fully hydrated by water at the conditions where oxidation of iron and production of hydrogen takes place. This type of reaction is possible between ca. $500{ }^{\circ} \mathrm{C}$ to ca $700{ }^{\circ} \mathrm{C}$. It would lead to a small consumption of water to provide the oxygen for the oxidation of iron. The remaining water would dissolve the expelled hydrogen and produce a seismic response consistent with observations. If scapolittisation and albitisation takes place above the zone of iron oxidation, this reaction might explain the continued conductivity above the zone of seismic reflectivity (Kühn et al. 2014, McGary et al. (2014)).

Albitisation requires supply of sodium and silica. Engvik et al. (2017) studied the processes related to albitisation in the Bamble region of Norway. They conclude that albitisation takes place after earlier scapolitisation. Breakdown of Cl-bearing amphibole occurs in two stages that ultimately results in expulsion of $\mathrm{H}_{2} \mathrm{O}$ and $\mathrm{Cl}$. Albitisation mobilises bivalent ions such as $\mathrm{Fe}^{2+}, \mathrm{Ca}^{2+}$ etc. and typically occurs at temperatures around $400{ }^{\circ} \mathrm{C}$. Albitisation, therefore, leads to iron ore formation and carbonates due to $\mathrm{CO}_{2}$ formed by the breakdown of scapolite. The combination of mineral reactions and fluid expulsion is believed by Engvik et al. (2017) to have caused transition between brittle and ductile properties at temperatures as high as 350 ${ }^{\circ} \mathrm{C}$ in the studied area. Fluid expulsion in this temperature region might also be the cause of the observed earthquakes at lower crustal levels.

Incidentally, serpentinization is also consistent with the temperature $\left(450-550^{\circ} \mathrm{C}\right)$ observed at around $20 \mathrm{~km}$ depth of the crust (Scribano et al. (2017)).

A lower crust, hydrated from below, is therefore likely to contain a suite of different minerals and fluid systems. 
The observed conductivity, the seismic response in $\mathrm{Vp}$ and $\mathrm{Vs}$, the seismicity and mechanical properties of an LCB below $20 \mathrm{~km}$ depth, above active subduction zones, and in some intracratonic settings, might be explained as follows:

- Supply of saline fluids to upper mantle/lower crust at conditions beyond amphibolite facies conditions will lead to the observed behaviour, and local conductivity zones at lower crustal levels.

- Mineral reactions related to oxidation of iron in clinopyroxene produce conductivity and seismic reflectivity due to hydrogen production in a depth interval having temperatures between ca. $700{ }^{\circ} \mathrm{C}$ and $450{ }^{\circ} \mathrm{C}$.

- Scapolittisation, serpentinsation and albitisation at lower temperatures, produce conductivity, carbonates, and water, leading to seismicity and brittle/ductile behaviour in a depth interval having temperatures between ca. $400{ }^{\circ} \mathrm{C}$ and ca. $450{ }^{\circ} \mathrm{C}$.

\section{3 Relationship between saline fluids and rifting}

Our conclusion is that rift localisation and rift development are influenced by subductionderived saline fluids as a result of their ability to significantly alter properties and composition of mantle and crust in these regions. This may be summarised as follows:

- Saline fluids, released in subduction zones produce permeability and increase ductility within the mantle.

- The fluid content also lowers the density of the astenospheric mantle and creates significant buoyancy relative to the surrounding mantle.

- Ascending fluids will lower solidus temperatures of the mantle and produce melting and volcanic activity separate from the more saline fluid systems.

- Saline fluid systems will be localised between the existing, or fossil, subduction trench, and the existing, or fossil, volcanic arc.

- High-pressured, saline fluids will invade the upper mantle by fracturing or diapiric flow.

- Above Moho depth, hot and saline fluids will cause mineralogical alterations that produce the LCBs involved in the localising of rifting and observed rift development.

- In the upper crust, observations from deep wells and cratons show that saline fluids invade the upper brittle parts of the crust, from below, where they may open up, or create fractures in the severely stressed crust.

- The invasion- and hydraulic fracturing process is also confirmed by the observation of frequent earthquakes around $10 \mathrm{~km}$ depth in the crust. This implies structural inheritance from fluids also in the brittle parts of the crust, due to fluid-filled fractures and lower resistance to shear stresses.

- Data from deep wells show that saline fluids also may be chemically bound in crustal rocks, at depth.

- The observation of large, fluid-filled, conductive zones in mantle and crust, may indicate future zones of rifting and salt deposition. 


\section{Salt production due to hydrothermal- and mineral dehydration processes during rifting}

\subsection{Behaviour of salt water/solutions as a function of pressure and temperature}

There are differences between salts in terms of their solubility and ability to bind crystal water. To simplify the thermodynamical behavior of such salt / water systems, only halite $(\mathrm{NaCl})$ is considered. Other chlorides and salt mixtures will behave quite similarly within certain limits. Their properties are especially important in terms of fractionation of different salts, but not so much for their properties as liquids, solids, or solutions in the form of liquids or vapors at elevated temperatures and pressures.

Fig. 17 shows the phase diagram presented by Coumou and Driesner (2009) of the system water and halite at different pressures and temperatures. This diagram shows the equilibrium state defined by fluid composition, pressure, and temperature, provided that the system is closed. It is well known that an open container containing salt water will dry out and precipitate solid salt even without boiling. However, this only applies if the evaporating water can escape freely, without increasing the fluid pressure. In a closed container, any increase in temperature will lead to evaporation and increased pressure that keeps the conditions on the 3D surfaces within the phase diagram shown in Fig. 17. With this in mind, we can better understand the different parts of the diagram and the behavior of open and closed saltwater systems in nature.

Figure 17. Equilibrium phase diagram for water and halite $(\mathrm{NaCl})$ at different $\mathrm{P} / \mathrm{T}$-conditions. (Modified from Coumou and Driesner (2009))

The halite liquidus surface (Fig. 17) is close to vertical and signals that if the salt content exceeds certain concentrations, solid salts will precipitate until the remaining liquid returns to the conditions given by this surface. The halite-liquidus surface at $100 \%$ salinity and atmospheric pressure, ends at about $800^{\circ} \mathrm{C}$, and above this point only molten salt is present. As can be seen from the diagram, the pressure will not affect much on the melting temperature of halite.

The surface marked $\mathrm{V}+\mathrm{L}+\mathrm{H}$ represents the equilibrium conditions where salt water will boil and create fresh steam and solid salt. This surface indicates that in order to produce solid salt and fresh steam by boiling salt water, the pressure will always be below approx. 400 bar. The necessary temperature to obtain boiling at this pressure is approximately $600^{\circ} \mathrm{C}$. Boiling at these conditions produces approximately $65 \mathrm{wt} \%$ salt and $35 \mathrm{wt} \%$ fresh steam. 
Lower pressures will allow boiling at lower temperatures and equilibrium conditions will remain along the $\mathrm{V}+\mathrm{L}+\mathrm{H}$ surface. If the temperature goes beyond $600^{\circ} \mathrm{C}$, pressure has to be lowered to keep the vapour fresh. Otherwise, the system enters the $\mathrm{V}+\mathrm{L}$ surface. Going above the conditions for the $\mathrm{V}+\mathrm{L}+\mathrm{H}$ surface means that it is no longer possible to produce solid salts in equilibrium with fresh vapours. Under conditions in salinity, pressure and temperature that intersects the $\mathrm{V}+\mathrm{L}$ surface, the system will produce a saline liquid and a slightly saline vapour, as long as conditions stay below the critical conditions. Above critical conditions, no liquids exist and the fluid will split into two vapours of different salinity. The salinity of the two is found by the intersection of a corde through the $\mathrm{V}+\mathrm{L}$ surface, at a given pressure and temperature. As the pressure is increased at a given temperature, the saline vapour and the less saline vapour becomes more and more similar, until finally becoming the same at the critical line. The position of this line along the salinity axis, defines the salinity of this supercritical vapour.

If a supercritical saline vapour is subjected to a lower pressure, while maintaining the same temperature, it will enter the region where it splits into a saline vapour and a less saline vapour. Buoyant forces will start to act on the two parts and if no mixing occurs, the lighter vapour may escape, and the system is no longer in equilibrium. Then the salt content of the remaining system will increase. Based on this, it becomes evident that a hot magmatic system operating at $\mathrm{V}+\mathrm{L}$ surface conditions, can produce two sets of fluids with different salinity, in the same region. If fluid inclusions form under such conditions, both types of fluids may be present.

It is also possible for real magmatic systems to produce entirely fresh vapour that leaves the system, while a denser brine or even solid salt is left behind. This is where interaction with fluid dynamics comes in. Given the right permeabilities, an escaping vapour may or may not be capable of lifting the brine out of the system. If capable, no extra salts are accumulating within the system. Otherwise, salinity will increase. As density of the different phases are a function of pressure, temperature and salinity, there are certain domains in real systems where salts might accumulate during hydrothermal circulation of saline fluids.

This process has been investigated by Coumou and Driesner (2009) for conditions similar to those of a black smoker system near oceanic spreading centra (Fig. 17).

This process has been investigated by Coumou and Driesner (2009) for conditions similar to a black-smoker system near oceanic spreading centers (Fig. 2). In a real situation, dissolution and precipitation of solids other than salt will affect the behavior of the phases in the entire system, alter the permeability and thus also interfere with the fluid paths and complicate the dynamic behavior. See also Kawamoto et al. (2012), Weis (2015).

\subsection{Solid salt precipitation in magmatic systems}

Lecumberri-Sanchez et al (2015) have collected data from-, and simulated, the formation of porphyry copper ores in magmatic systems. Fluid inclusions in these ores, document the 
presence of highly saline fluids during their formation. In $90 \%$ of the cases, halite-bearing inclusions homogenize by halite dissolution. They also found that pressure estimates based on homogenization conditions for the inclusions, in many cases, exceeded the area's modeled lithostatic pressure. Since this is very unlikely, they concluded that salts had already precipitated, and were trapped along with some fluids, while the inclusions were forming. A numerical simulation of a magma chamber at $5 \mathrm{~km}$ depth, releasing fluids to the hydrothermal circulation above, showed that salt precipitation was possible above ca. $4 \mathrm{~km}$ depth due to boiling. Over time, the mass of salt would increase and generally accumulate below $2 \mathrm{~km}$ depth. Coumou and Driesner (2009) performed similar thermodynamic and fluid dynamic simulations. The heat source in their system was placed under the seabed at some water depth, mimicking a black smoker system in the vicinity of a deep water, oceanic spreading ridge. Their circulating fluid was cold seawater, being heated in the subsurface before ascending to the seabed again. Heating such cold fluids to potentially phase separating temperatures requires much energy. This circulation system maintains the hydrostatic head of the water column above the seabed, even during boiling above the heat source. Their simulation is, therefore, not entirely relevant for a rifting situation on land, where the lithostatic pressure is initially replaced by hydrostatic pressure, which eventually is replaced by the pressure of a column of flowing vapour - and even back to lithostatic conditions if the flow channels clog up by precipitated minerals.

Such conditions were also the subject of numerical simulations by Weis (2015), when studying the hydrothermal conditions of porphyry copper formation. His model includes multiphase flow of compressible, variably miscible $\mathrm{H}_{2} \mathrm{O}-\mathrm{NaCl}$ fluids, with an accurate thermodynamic description of phase relations and fluid properties, as well as a dynamic permeability model, which describes the transition from brittle to ductile rock and even hydraulic fracturing.

Porphyry deposits are associated with a decrease in temperature in the ore forming fluids from initially $600-700{ }^{\circ} \mathrm{C}$ to values between 350 and $450{ }^{\circ} \mathrm{C}$. These are all temperatures well above the brittle-ductile conversion zone for most crustal rocks. As the hot fluids rise under near lithostatic pressures, they alter the critically stressed and brittle rocks to ductile rocks, thereby reducing permeability. This in turn leads to pressure build-up and an incoherent, geyser-like flow. Within this regime, fluids are flowing, evaporating and precipitating salts. Although relevant, the simulations by Weis (2015), Lecumberri-Sanchez et al (2015) and Coumou and Driesner (2009) are not completely mimicking a more dynamic rifting system. This is because a rifting system involves more mass, more saline fluids, and more heat, than a relatively static, volcanic magma chamber. Rifting also enables the crust to open up more easily to fluid flow due to faulting and spreading. This will greatly influence the development of the dynamic head experienced by the ascending fluids during different phases of the rifting.

\subsection{Rifting and salt accumulation}

As far as we know, there have been no attempts to numerically model the simultaneous mantle upwelling and circulation, the rift mechanics, the thermodynamic behavior of liquids and salts, 
the change in mineral systems and rock properties as a function of changing conditions during rift initiation and development. Even if this could be done accurately, the result would be depending heavily on defining the correct initial conditions for all relevant components of the system. This implies a return to the question of inherited properties and observations made in the crust and mantle.

\subsubsection{Fluid saturation of mantle masses}

As a result of the saline fluids being brought down by subduction and transmitted upwards in the mantle, a very deep, nearly continuous saline fluid reservoir is created within all mantle wedges. As seen from MT measurements in fossil subduction zones and cratons, this reservoir may exist for hundreds of millions of years. Although lithostatic pressures act on these fluids, a major portion is kept in place in pores that are staying open due to salinity, pressures, and temperatures in these zones. The upper asthenospheric- and upper lithospheric mantles are mechanically weakened by these processes and are hydrated with salt- and silica-rich fluids, perhaps to depths of several hundred $\mathrm{km}$. In the domain where temperatures exceed $700{ }^{\circ} \mathrm{C}$ and dihedral angles are altered to become less than $60^{\circ}$ due to a combined effect of changes in fluids, pressures, and temperatures, a large portion of the saline fluids make intergranular space for themselves.

The hydrated mantle expands slightly during subduction as more and more fluids are intruded and stored. As the fluid network expands towards the low permeability zone in the upper mantle, it also expands laterally. A balance will develop between the fluid pressure required to compress the mantle laterally and the pressure required by the ascending fluids to penetrate the less permeable mantle. Most of the fluids trapped in the mantle during this process will remain there until the pore spaces are overfilled. However, the intrusion of increasing amounts of saline fluids creates also more pore space due to their ability to open up more pore volume by reducing the dihedral angles between mineral grains. For these reasons, a significant volume of liquid is required to overfill a fluid-saturated mantle, or until buoyancy begins to apply to the entire hydrated mantle volume, causing mantle melts and fluids to move upwards. Consequently, a buoyant mantle, requires large volumes of fluids to satisfy the conditions of buoyancy (Esedo et al. (2012); Raddick et al. (2002)). Buoyancy is self-sustaining, mainly as a result of the lowering of mantle pressure during ascent.

Thus, it follows, that during extended periods of subduction, where the continents assemble into supercontinents, significant volumes of the oceanic water will be subducted and stored semi-permanently in the mantle. These processes are resulting in (i) lower sea levels, (ii) an expanded upper mantle, and (iii) slow-down of the Earth's rotation and an increased length of day. In practice, only volcanism and deep transversal faulting above subduction zones able of removing significant parts of the salts and fluids from the mantle during subduction events. This implies that a buoyant mantle is required in order to bring most of the subducted fluids back to the surface again. 


\subsubsection{Updoming and initial rifting}

Esedo et al. (2012) studied several major rift margins and conclude that updoming of 1-2 km, prior to rifting, is a common occurrence. Updoming is the result of combined isostatic effects and dynamic push from the upwelling mantle.

Two independent studies, Petrunin et al. (2020) and Chang et al. (2011), using different seismic technologies and modelling, have presented overlapping data, consistent with mantle buoyancy, mantle convection, and fluids/melts ascending in the entire Red Sea and Afar region. The driving force is the water content of the mantle, all the way down to $600 \mathrm{~km}$ depth.

A study by d'Almeida (2010) claims that available geological data suggests that the Red Sea region started its active evolution in the Cretaceous. A Cretaceous-Paleogene trough predated the later Oligocene-Quaternary rift and covered this region completely or partially. During later phases, the region was subjected to uplifting and denudation, in between the rifting phases.

Stockli and Bosworth (2019) and Yao et al. (2017) also model the evolution of the Red Sea involving mantle upwelling and a low angle detachment fault connecting the initial rift and the lithospheric, astenospheric boundary (LAB).

Thus, the Red Sea may constitute a type locality for current (active) salt deposition from the mantle within an updomed rift system.

Buoyancy within a hydrated mantle segment is a self-sustaining result of the lowering of pressure during ascent and due to rifting of the crust, caused by updoming and far field stresses.

Esedo et al. (2012), Raddick et al. (2002), and Liao et al. (2017) have also studied the lithospheric thinning in relation to rifting. During the early phases of rifting, a hydrated and partially melted astenospheric mantle, may induce lithospheric thinning and weakening by causing lithospheric mantle dripping. The lithosphere is thinned from below as selective decompression melting takes place and high-density cumulates sink in. More water tends to speed up the thinning process. As modelled by Esedo et al. (2012), the upwards directed velocity of the astenospheric mantle below the center of a rifting zone, can be as high as 30 $\mathrm{cm} /$ year across a $300 \mathrm{~km}$ width. This would circulate hydrated astenospheric mantle up from $200 \mathrm{~km}$ depth in just over 600000 years.

According to Esedo et al. (2012), the circulation brings astenospheric mantle up to the $25 \mathrm{~km}$ level, which is in the middle of most observed LCBs. Previous weak zones, created during formation of the LCB, are probably reactivated - or never deactivated, to let the melts rise further. The magma heats and transforms the LCB and lithosphere locally, thereby causing the observed density stratification. Depending on the character of the rising mantle, magma may also be produced higher up due to decompression melting, intruding the crust and may even reach the surface prior to rifting.

The process of creating shallow, astenospheric melts, has been confirmed by Sanfilippo et al. (2019), by trace element analysis of volcanic rocks from the western Arabian Peninsula, 
contemporaneous with the Red Sea rifting. They concluded that the magmatic evolution occurred in magma chambers located at-, or close to the crust-mantle boundary, constrained by fractionation of olivine, clinopyroxene, plagioclase and Ti-Fe oxides (Sanfilippo et al., 2019). This was regarded consistent with the idea that the sub-continental mantle in this region may have formed in a supra-subduction environment with residual amphiboles. Thus, they both confirm the lithology of the lower crust/upper mantle, the process leading to it, and they, therefore, also confirms that the hot fluids were transported upwards from greater depths (Sanfilippo et al., 2019).

According to Johnson (2014), the Arabian Nubian Shield by the Red Sea, is composed of amphibolites, granulites and greenshist facies rocks of $650 \mathrm{Ma}$ to $540 \mathrm{Ma}$ age. This represents a similar crustal system as the one observed in the Canadian shield, by Hill et al. (2021). Touret (2009) confirms that these crustal rocks are the result of mantle upwelling and massive fluid flow. Bottomley et al. (2005) have confirmed that they contain dense brines, by sampling similar rocks in the Canadian shield.

All of this indicates that the Red Sea region might be capable of producing large salt deposits from mantle- and crustal sources.

\subsubsection{Salt deposition processes}

The combination of upwelling and initial rifting may result in a confined basin, isolated from the sea. Upwelling of astenospheric mantle brings with it the fluids that caused the upwelling and participated in the thinning of the lithosphere. These fluids end up within the initial rift basin where they may precipitate salts. Saline fluids are continually expelled from the porous upwelled mantle rocks or expelled from cooling melts, resulting in fluid pressure buildup and invasion of the crust by masses of supercritical, high pressure, saline vapour. The hot fluids also transport heat upwards and, thus, raise the brittle - ductile transition zone. In the ductile zone, fluid flow will take place as diapiric and possibly, intermittent flow as modelled by Weis (2015).

As shown earlier, crustal fluids may typically have salinities from $15 \%$ to $50 \%$. They might therefore represent condensates of the denser part of a phase-separated, supercritical vapour at depth. An intermingled, or separate fluid system may also exist, carrying less salts and more $\mathrm{CO}_{2}$. According to Kawamoto et al. (2012), phase separation occurs at depths greater than 80$90 \mathrm{~km}$. Hence, the upper part of the mantle and crust above subduction zones, may contain concentrated saline vapours similar to what is observed in the crust. With a typical water content of $5 \mathrm{wt} \%$ in magmatic systems (Manning (2004), Weis (2015)), the actual salt content of the hydrated, upper mantle, might locally exceed $1-2 \mathrm{wt} \%$.

Two processes bring salts and saline fluids up to the surface during this early phase of rifting. Magmatism and formation of sills and dykes in the upper crust (Stern et al. (2019)), which lead to phase separation and boiling of saline fluids that are already present in the fractured crust. In addition, the magma, itself, expells hot saline fluids as it cools. As rifting opens up more 
accommodation volume by extention (more and more fractures in the crust), the expelled, hot mantle fluids ascend higher and higher under hydrostatic pressure. As seen from Fig. 17, a $1000{ }^{\circ} \mathrm{C}$ saline fluid at pressures corresponding to a hydrostatic head at $20 \mathrm{~km}$ depth (ca. 2000 bar), will be at the verge of phase-separation. A slight lowering of the pressure is causing a partioning of the vapour system, into one buoyant- and one less buoyant salt bearing vapour. Further lowering of pressure, or influx of fluids expelled at lower levels, will intensify this process. Whether or not this leads to production of solid salt in situ, depends on the ability of the two vapour components to split up and not recombine. This is mainly a function of the density difference between the saline and the fresher vapour, the permeability of the flow path, flow velocity and turbulence. Over time, the surrounding rocks along the flow path, will have warmed sufficiently to allow hot fluids boiling below- or at reaching the surface. Evaporation and formation of solid salts will occur along the ascending route, and finally, at the surface. As simulated by Coumou and Driesner (2009), Weis (2015) and Lecumberri- Sanchez et al. (2015), this requires a pressure domain created by a hydrostatic head equivalent to $3-4 \mathrm{~km}$ water depth. Once the hot fluids reach this depth, vigorous phase separation takes place, where the fresh vapour is too light to displace and transport heavy brines and solid salts. Thus, accumulation of heavy brines and solid salt occurs.

In a rifting system, where the hydrostatic head is different from that of a black smoker system at the seabed, or beneath a fluid-saturated volcanic cone (Coumou and Driesner (2009), Weis (2015)), the depth to salt deposition might be greater. However, the depth where boiling might occur is limited to a depth that does not produce a dynamic pressure of more than ca. 400 bar. As the upper crust is heated to temperatures at-, or above $400{ }^{\circ} \mathrm{C}$ by fluids, magma or mantle heat, it becomes ductile. Below this depth, fluids and salts will be displaced by the denser, ductile rocks or by magmatic sills and dykes (Fig. 18).

Figure 18. Invasion of crustal rocks by hot magmatic sills and dykes. Dykes and sills will increase the flow of energy and fluids between the mantle and crust. This leads to enhanced salt expulsion and precipitation. (Modified from Stern et al. (2019)).

As the system cools, the phase separation zone moves to deeper levels. However, the supply of salt vapour with high temperatures and pressures from the deep magmatic system continues to transport salts towards the rift zone, associated with changes in the thermodynamic conditions and the tectonics associated with the initial doming and rifting. The deep salt reservoir is partly displaced by sill intrusions and partly depleted by a continued supply of hot and pressurised salt-bearing fluids from the magmatic system. Thus, this deep salt reservoir becomes depleted, while solid salts accumulate in the lower sections of the rift geometry. At relatively low pressures, especially related to magmatic intrusions, the escaping vapours might also result in molten salts at temperatures above ca. $800{ }^{\circ} \mathrm{C}$. This salt magma may also escape to the surface and solidify there. 
As salts are transported out from the deep crust and mantle, the base of the rift will subside, even before subsidence caused by decreasing temperature in the upper mantle and volcanic intrusions. This also produces accommodation space for arriving salts.

The Afar region in Ethiopia may serve as an analogy to this stage of the process, where volcanics penetrate salt deposits and spread out on the surface, indicating that the salts/saline fluids, with low density compared to the lavas, arrived, and solidified first. The initial updoming phase is on the return and subsidence of the basin is occurring because of cooling, rifting, and salt expulsion from crust and mantle to the surface.

The last stages of salt production involve exhumation of the upper exposed hydrated mantle, which might involve further subsidence and invasion of the rift by the ocean. Boiling and solid salt production might still take place even at ca. 400 bar pressure if saline fluids are expelled at $600{ }^{\circ} \mathrm{C}$ or more. This implies that solid salts might still be produced by subsea boiling, even beneath $800 \mathrm{~m}$ water depth and $1.5 \mathrm{~km}$ salts on top of a hot mantle. Escaping vapour would then dissolve salts above the boiling zone, and then transport them further upwards while reprecipitating them higher up due to cooling. Thus, salt producton within rift systems might produce both pre-rift salts and syn-rift salts. With full oceanic spreading, the salt reservoir in the mantle is gradually emptied. However, salts may still be produced into the rift from crustal rocks.

Boiling conditions at newly formed oceanic crust, is not likely to produce solid salts, as salts and vapour will recombine rapidly. Separation of vapour and salts/brines within sediments or mantle rocks, may produce brines that leak out on the seabed where subsea brine lakes form and where later cooling again may create solid salts.

Even after thick salt deposits have been formed, magma intrusions may preferentially penetrate salt strata occupied by salts carrying crystal water e.g., bishofite, carnallite etc. Such salts are known to melt in their crystal water at temperatures above $120{ }^{\circ} \mathrm{C}$. (Schofield et al. (2014). This may lead to escape and refinement of these salts higher up in the stratigraphy, or even ponding at the seabed.

\subsubsection{Estimation of salt quantities}

In a rift system like in the Red Sea, mantle fluids may have been expelled due to mantle circulation for more than 10 million years. Even if we reduce the astenospheric convection speed from $30 \mathrm{~cm} /$ year (Esedo et al. (2012)) to $3 \mathrm{~cm} /$ year, enough time will have elapsed to circulate more than $300 \mathrm{~km}$ of mantle upwards. If we assume that $1 \mathrm{wt} \%$ salts have been expelled from the mantle, the average layer of pure salt across the entire, $300 \mathrm{~km}$ wide rift, might exceed $3 \mathrm{~km}$. This amount does not include salts produced by hydrothermal circulation of seawater, muds, sediments, carbonates, and anhydrite, which are often interbedded in salt deposits. 
Because there are obvious supplies of saline brines in the mantle from long lasting- and repeated episodes of subduction in the Red Sea area (Blasband (2006), Fritz et al. (2013), Johnson (2014), the potential for salt formation is certainly present. The heat capacity of an upwelling mantle of the Red Sea type, is large, and the only real limitation of this system, is preservation of the formed salts long enough for humans to observe them.

As the rift topography will promote secondary flow of salts and brines towards the center of the rift, while leaving some of the salts in deep mini basins, the salt thickness will vary a great deal across the $300 \mathrm{~km}$ wide, or so, rift. Fig. 19 presents the main stages of a salt accumulating rift system, as typified by the Red Sea area.

Figure 19. Three stages in the evolution of salt accumulation in rifts. A) Upwelling of astenospheric, hydrated mantle above fossil subduction zone, forming of an elevated, isolated basin. Initial rifting of crust along major detachment zone on top of hydrated astenosphere caused by gravitational- and regional pull, influx of saline fluids and salts into the basin (Modified from Yao et al. (2021)). B) Continued rifting and influx of salts in isolated rift, gradually subsiding due to removal og salts from the mantle, later entering the thermal subsidence stage (Modified from Lopez-Garcia et al. (2020)). C) The salt deposits have been split by the rift and the depression has been invaded by the ocean, formation of oceanic crust is in progress, salts are subjected to gravity flow into the lower sections. Some salts are still expelled from the underlying mantle, beneath and within sediments and salts (Modified from Mohriak et al. (2019)). DF- Detachment fault. LAB - Lithosphere- Astenosphere Boundary. Green rectangles indicate the approximate extent of the region affected by rifting and salt expulsion during the three phases

\section{Conclusions}

Giant salt deposits are the result of several stages of the Wilson cycles. The process is intitiated by the saturation of oceanic crust and sediments with saline fluids. Water and salts are later expelled from this crust in subduction zones and enter into the mantle wedge above the subducting slab. This leads to ascending supercritical fluids in fluid-invaded, permeable parts of the wedge, as well as ascending melts below volcanic arcs. The expelled fluids alter the strength and buoyancy of the mantle wedge, thereby preparing it for upwelling in concert with crustal plate movements. Ascending mantle fluids convert upper mantle rocks into lower crustal rocks by metamorphic processes, thereby producing lower crustal bodies (LCBs), allowing brittle deformation to take place at lower crustal levels. Later rifting, mantle upwelling, and expulsion of hot, saline fluids, therefore, may lead to the commonly observed rift geometries as well as the observable salt accumulations in rift basins - if conditions favouring salt preservation are present. 


\section{Acknowledgements}

\section{References}

Albright, J. L., Lueth V. W., 2003, Pecos diamonds-quartz and dolomite crystals from the Seven Rivers Formation outcrops of southeastern New Mexico. New Mexico Geology, 25, No.3, 63-74.

Allen, P. A., Allen, J. R., 2005, Basin analysis: principles and applications, Second edition, Blackwell Publishing, ISBN 0-0632-05207-4.

Allen, J., Beaumont, C., 2016, Continental margin syn-rift salt tectonics at intermediate width margins. Basin Research, 28, 598-633.

Araya Vargas, J., Meqbel, N., Ritter, O., Brasse, H., Weckmann, U., Yáñez, G., Godoy, B., 2019, Fluid Distribution in the Central Andes Subduction Zone Imaged With Magnetotellurics, Journal of Geophysical Research, 124-4, 4017-4034.

Augustin, N., van der Zwan, F., M., Devey, C., W., Brandsdóttir, B., 2021, 13 million years of seafloor spreading throughout the Red Sea Basin, Nature Communications, 12, 2427.

Barnes, J. D., Manning C. E., Scambelluri, M., Selverstone, J., 2018, Ch. 8, The Behavior of Halogens During Subduction-Zone Processes, Daniel E. Harlov, D.E., Aranovich, L., (Eds), The Role of Halogens in Terrestrial and Extraterrestrial Geochemical Processes Surface, Crust, and Mantle, Springer Geochemistry, ISSN 2366-6293 ISSN 2366-6285.

Bauer, S.J., Gardner, W. P., Lee, H., 2019, Noble Gas Release from Bedded Rock Salt during Deformation, Hindawi Geofluids, Article ID 2871840, 12 pages.

Bebout, G. E., Barton, M. D., 1993, Metasomatism during subduction: products and possible paths in the Catalina Schist, California ChemicaI Geology, 108, 61-92.

Bedrosian, P.A., 2007, MT+, Integrating Magnetotellurics to Determine Earth Structure, Physical State, and Processes, Surv. Geophys., 28, 121-167.

Behr, W. M., Platt, J. P., 2014, Brittle faults are weak, yet the ductile middle crust is strong: Implications for lithospheric mechanics, Geophysical Research Letters, 41, 8067-8075.

Belusov, V., V., 1966, Modern concepts of the structure and development of the Earth's crust and the upper mantle of continents, Quarterly Journal of the Geological Society, 122, 293314.

Blasband, B., 2006, Neoproterozoic Tectonics of the Arabian-Nubian Shield, GEOLOGICA ULTRAIECTINA Mededelingen van de Faculteit Geowetenschappen Universiteit Utrecht No. 256, ISBN-10: 90-5744-119-5 ISBN-13: 978-90-5744-119-6

Bonner IV, L. R., 2015, A magnetotelluric investigation of shallow conductivity sources beneath the Cascadia Volcanic Arc, A PROJECT submitted to Oregon State University, 
University Honors College in partial fulfillment of the requirements for the degree of Honors Baccalaureate of Science in Physics.

Booker, J., Favetto, A., Pomposiello, M., C., 2004, Low electrical resistivity associated with plunging of the Nazca flat slab beneath Argentina, Nature, 429, 399-403.

Bottomley, D. J., Clark, I. D., Battye, N., Kotzer, T., 2005, Geochemical and isotopic evidence for a genetic link between Canadian Shield brines, dolomitization in the Western Canada Sedimentary Basin, and Devonian calcium-chloridic seawater, Can. J. Earth Sci. 42, 2059-2071.

Braitsch, O., 1971, Salt deposits their origin and composition, Springer-Verlag, ISBN 3-54005206-2.

Brasse, H., Lezaeta, P., Rath, V., Schwalenberg, K., Soyer, W., Haak, V., 2002, The Bolivian Altiplano conductivity anomaly, Journal of Geophysical Research, 107, NO. B5, 2096.

Brune, S., Heine, C., Clift, P. D., Pérez-Gussinyé, M., 2017, Rifted margin architecture and crustal rheology: Reviewing Iberia-Newfoundland, Central South Atlantic, and South China Sea, Journal of Marine and Petroleum Geology,79, 257-281.

Cagnioncle, A-M., Parmentier, E. M., Elkins-Tanton, L. T., 2007, Effect of solid flow above a subducting slab on water distribution and melting at convergent plate boundaries, Journal of Geophysical Research, 11, 19 pages.

Cai, C., Wiens, D. A., Shen, W., Eimer, M., 2018, Water input into the Mariana subduction zone estimated from ocean-bottom seismic data, Nature, 563, 389-392.

Chang, S-J., Merino, M., Van der Lee, S., Stein, S., Stein, C. A., 2011, Mantle flow beneath Arabia offset from the opening Red Sea, Geophysical Research Letters, 38, L04301.

Chen, S., Hiraga, T., Kohlstedt, D. L., 2006, Water weakening of clinopyroxene in the dislocation creep regime, Journal of Geophysical Research, 111, 14pages.

Comeau, M. J., Unsworth, M. J., Ticona, F., Sunagua, M., 2015, Magnetotelluric images of magma distribution beneath Volcán Uturuncu, Bolivia: Implications for magma dynamics, Geology, 43; no. 3, 243-246.

Coumou D., Driesner, T., 2009, Phase separation, brine formation, and salinity variation at Black Smoker hydrothermal systems, Journal of Geophysical Research, 114, 16pages.

d'Almeida, 2010, Structural evolution history of the Red Sea Rift, Geotectonics, 44, 271-282

Davey, F.J., Ristau, J., 2011, Fore-arc mantle wedge seismicity under northeast New Zealand, Tectonophysics, 509, 272-279.

Debure, M., Lassin, A., Marty, N. C., Claret, F., Virgone, A., Calassou, S., Gaucher, E. C., 2019, Thermodynamic evidence of giant salt deposit formation by serpentinization: an 
alternative mechanism to solar evaporation, Nature Scientific Reports, 9, 11720, https://doi.org/10.1038/s41598-019-48138-9.

Emmermann, R., Lauterjung, J., 1997, The German Continental Deep Drilling Program KTB: Overview and major results, Journal of Geophysical Research, 102, No. B8, 18,179-18,201.

Engvik, A. K., Taubald, H., Solli, A., Grenne, T., Austrheim, H., 2018, Dynamic Metasomatism: Stable Isotopes, Fluid Evolution, and Deformation of Albitite and Scapolite Metagabbro (Bamble Lithotectonic Domain, South Norway), Hindawi Geofluids, 2018, ID 9325809, 22 pages.

Esedo, R., Van Wijk, J., Coblentz, D., Meyer, R., 2012, Uplift prior to continental breakup: Indication for removal of mantle lithosphere?, Geosphere, 8, no. 5, 1078-1085, doi:10.1130/GES00748.1.

Faccenna, C., Oncken, O., Holt, A. F., Becker, T. W.,2017, Initiation of the Andean orogeny by lower mantle subduction, Earth and Planetary Science Letters, 463, 189-201.

Fritz, H., Abdelsalam, M., Ali, K. A., Bingen, B., Collins, A. S., Fowler, A. R., Ghebreab, W., Hauzenberger, C. A., Johnson, P. R., Kusky, T. M., Macey, P., Muhongo, S., Stern, R. J., Viola, G., 2013, Orogen styles in the East African Orogen: A review of the Neoproterozoic to Cambrian tectonic evolution, Journal of African Earth Sciences, 86, 65-106.

Ghanbarzadeha, S., Hesseb, M., A., Prodanovi, M., 2017, Percolative core formation in planetesimals enabled by hysteresis in metal connectivity, PNAS, 114, 51, 13406-13411.

Glassley, W. E., 2001, Elemental composition of concentrated brines in subduction zones and the deep continental crust, Precambrian Research 105, 371-383.

Grevemeyer, I., Ranero, C. R., Ivandic, M., 2018, Structure of oceanic crust and serpentinization at subduction trenches, Geosphere, 14, no. 2, 395-418,

doi:10.1130/GES01537.1.

Grove, T. L., Chatterjee, N., Parman, S. W., Médard, E., 2006, The influence of H2O on mantle wedge melting, Earth and Planetary Science Letters, 249, 74-89.

Gueydan, F., Morency, C., Brun, J-P., 2008, Continental rifting as a function of lithosphere mantle strength, Tectonophysics, 460, 83-93.

Gueydan, F., Précigout, J., Montés, L.G.J., 2014, Strain weakening enables continental plate tectonics, Tectonophysics, 631, 189-196.

Guo, X., Yoshino, T., Shimojuku, A., 2015, Electrical conductivity of albite-(quartz)-water and albite-water- $\mathrm{NaCl}$ systems and its implication to the high conductivity anomalies in the continental crust, Earth and Planetary Science Letters, 412, 1-9.

Gutscher, M-A., Spakman, W., Bijwaard, H., Engdahl, E. R., 2000, Geodynamics of flat subduction: Seismicity and tomographic constraints from the Andean margin, Tectonics, 19, No. 5, 814-833. 
Hacker, B. R., Abers, G. A., Peacock, S. M., 2003, Subduction factory 1. Theoretical mineralogy, densities, seismic wave speeds, and $\mathrm{H} 2 \mathrm{O}$ contents, Journal of geophysical Research, 108, No. B1, 2029, doi:10.1029/2001JB001127.

Hacker, B. R., Abers, G. A., Peacock, S. M., Holloway, S. D., 2003, Subduction factory 2. Are intermediate-depth earthquakes in subducting slabs linked to metamorphic dehydration reactions?, Journal of Geophysical Research, 108, No. B1, 2030, doi:10.1029/2001JB001129.

Harlaux, M., Mercadier, J., Bonzi, W. M-E., Kremer, V., Marignac, C., Cuney, M., 2017, Geochemical Signature of Magmatic-Hydrothermal Fluids Exsolved from the Beauvoir RareMetal Granite (Massif Central, France): Insights from LA-ICPMS Analysis of Primary Fluid Inclusions, Hindawi Geofluids , 2017, 25 pages.

Heise, W., Caldwell, G., Hill, G. J., Bennie, S. L., Wallin, E., Bertrand, E. A., 2012, Magnetotelluric imaging of fluid processes at the subduction interface of the Hikurangi margin, New Zealand, Geophysical Research Letters, 39, L04308.

Heise, W., Caldwell, T. G., Bannister, S., Bertrand, E. A., Ogawa, Y., Bennie, S. L., Ichihara, H., 2017, Mapping subduction interface coupling using magnetotellurics: Hikurangi margin, New Zealand, Geophysical Research Letters, 44, 9261-9266.

Hensen, C., Wallmann, K., Schmidt, M., Ranero, C. R., Suess, E., 2004, Fluid expulsion related to mud extrusion off Costa Rica-A window to the subducting slab, Geology, 32 (3), 201-204.

Hess, H., H., 1933, The problem of serpentinization and the origin of certain chrysotile. asbestos, talc, and soapstone deposits, Economic Geology, 28, 634-657.

Hill, G.J., Roots, E.A., Frieman, B.M., Haugaard, R., Craven, J.A., Smith, R.S., Snyder, D.B., Zhou, X., Sherlock, R., 2021, On Archean craton growth and stabilisation: Insights from lithospheric resistivity structure of the Superior Province, Earth and Planetary Science Letters, $562,2021,116853$.

Holness, M. B., 1992, Equilibrium dihedral angles in the system quartz-CO2 $-\mathrm{H} 2 \mathrm{O}-\mathrm{NaCl}$ at $800^{\circ} \mathrm{C}$ and 1-15 kbar: the effects of pressure and fluid composition on the permeability of quartzites, Earth and Planetary Science Letters, 114-1, 171-184.

Holness, M. B., 2006, Melt-Solid Dihedral Angles of Common Minerals in Natural Rocks, Journal of Petrology, 47 No.4, 791-800.

Holness, M. B., Graham, C. M., 1991, Equilibrium dihedral angles in the system $\mathrm{H} 2 \mathrm{O}-\mathrm{CO} 2-\mathrm{NaCl}$-calcite, and implications for fluid flow during metamorphism, Contributions to Mineralogy and Petrology, 108, 3, 368-383.

Hovland, M., Kutznetsova, T., Rueslåtten, H., Kvamme, B., Johnsen, H. K., Fladmark, G. E., Hebach, A., 2006a, Sub-surface precipitation of salts in supercritical seawater. Basin Research, 18-2, 221-230. 
Hovland, M., Rueslåtten, H., Johnsen, H. K., Kvamme, B., Kutznetsova, T., 2006b, Salt formation associated with sub-surface boiling and supercritical water, Marine and Petroleum Geology, 23, 855-869.

Hovland, M., Rueslåtten, H., Johnsen, H. K., 2018, Large salt accumulations as a consequence of hydrothermal processes associated with 'Wilson cycles': A review Part 1: Towards a new understanding, Marine and Petroleum Geology, 92, 987-1009.

Hovland, M., Rueslåtten, H., Johnsen, H. K., 2018, Large salt accumulations as a consequence of hydrothermal processes associated with 'Wilson cycles': A review, Part 2: Application of a new salt-forming model on selected cases, Marine and Petroleum Geology, 92, 128-148.

Huang, R., Ding, X., Lin, C-T., Zhan, W., Ling, M., 2018, Effect of saline fluids on chlorine incorporation in serpentine, Solid Earth Sciences, 3-3, 61-66.

Huang, Y., Nakatani, T., Nakamura, M., McCammon, C., 2019, Saline aqueous fluid circulation in mantle wedge inferred from olivine wetting properties, Nature Communications, https://doi.org/10.1038/s41467-019-13513-7.

Huang, Y., Nakatani, T., Nakamura, M., McCammon, C., 2020, Experimental constraint on grain-scale fluid connectivity in subduction zones, Earth and Planetary Science Letters, 552, 116610.

Hyndman, R. D., Shearer, P. M., 1989, Water in the lower continental crust: modelling magnetotelluric and seismic reflection results, Geophys. J. Int., 98, 343-365.

Johnson, H. P., Pruis, M.J., Van Patten, D., 2000, Density and Porosity of the Upper Oceanic Crust from Seafloor Gravity Measurements, Geophysical research letters, 27, No. 7, 10531056.

Johnson, P., R., 2014, An Expanding Arabian-Nubian Shield Geochronologic and Isotopic Dataset: Defining Limits and Confirming the Tectonic Setting of a Neoproterozoic Accretionary Orogen, The Open Geology Journal, 8, 3-33.

Kawamoto, T., Kanzakib, M., Mibec, K., Matsukage, K. N., Ono, S., 2012, Separation of supercritical slab-fluids to form aqueous fluid and melt components in subduction zone magmatism, PNAS | 2012 109, No. 46, 18695-18700.

Kawamoto, T., Yoshikawab, M., Kumagaia, Y., Mirabueno, Ma. H. T., Okuno, M., Kobayashie, T., 2013, Mantle wedge infiltrated with saline fluids from dehydration and decarbonation of subducting slab, PNAS, 110, No. 24, 9663-9668.

Kelley, D. S., Delaney, J. R., 1987, Two-phase separation and fracturing in mid-ocean ridge gabbros at temperatures greater than $700^{\circ} \mathrm{C}$, Earth and Planetary Science Letters, 83,1-4, 5366. 
Kelley, D.S., Robinson, P. T., Malpas, J. G., 1992, Processes of brine generation and circulation in the oceanic crust: Fluid inclusion evidence from the Troodos Ophiolite, Cyprus, JGR Solid Earth, 97, B6, 9307-9322.

Kendrick, M. A., Hémond, C., Kamenetsky, V. S., Danyushevsky, L., Devey, C. W., Rodemann, T., Jackson, M. G., Perfit, M. R., 2017, Seawater cycled throughout Earth's mantle in partially serpentinised lithosphere, Nature Geoscience, 10, 222-229.

Kenji, M., Toshitsugu, F., Atsushi, Y., 1998, Connectivity of aqueous fluid in the Earth's upper mantle, Geophysical Research Letters, 25-8, 1233-1236.

Kietäväinen, R., 2017, Deep Groundwater Evolution at Outokumpu, Eastern Finland: From Meteoric Water to Saline Gas-Rich Fluid. Geological Survey of Finland, Espoo. 37 pages.

Kozlovsky Ye. A., The Superdeep Well of the Kola Peninsula, 1987, Springer-Verlag, ISBN 0-387-16416-2.

Kühn, C., Küster, J., Brasse, H., 2014, Three-dimensional inversion of magnetotelluric data from the Central Andean continental margin, Earth, Planets and Space, 66:112.

Laumonier, M., Gaillard, F., Muir, D., Blundy, J., Unsworth, M., 2017, Giant magmatic water reservoirs at mid-crustal depth inferred from electrical conductivity and the growth of the continental crust, Earth and Planetary Science Letters, 457,173-180.

Lecumberri-Sanchez, P., Steele-MacInnis, M., Weis, P., Driesner, T., Bodnar, R. J., 2015, Salt precipitation in magmatic-hydrothermal systems associated with upper crustal plutons, Geology, 43-12,1063-1066.

Li, W., Ni, H., 2020, Dehydration at subduction zones and the geochemistry of slab fluids, Science China Earth Sciences, 63-12, 1925-1937

Li, X., Ma, X., Chen, Y., Xue, S., Varentsov, I. M., Bai, D., 2020, A plume-modified lithospheric barrier to the southeastward flow of partially molten Tibetan crust inferred from magnetotelluric data, Earth and Planetary Science Letters, 548, 116493.

Liao, J., Wang, Q., Gerya, T., Ballmer, M. D., 2017, Modeling craton destruction by hydration-induced weakening of the upper mantle. Journal of Geophysical Research: Solid Earth, 122, 18 pages.

Ligi, M., Bonatti, E., Bosworth, W., Ronca, S., 2019, Oceanization Starts at Depth During Continental Rupturing in the Northern Red Sea, In: Geological Setting, Palaeoenvironment and Archaeology of the Red Sea, Najeeb M. A. Rasul, Ian C. F. Stewart, (Eds), Springer Nature Switzerland AG 2019, ISBN 978-3-319-99407-9.

López-García, J.M., Moreira, D., Benzerara, K., Grunewald, O., López-García, P., 2020, Origin and Evolution of the Halo-Volcanic Complex of Dallol: Proto-Volcanism in Northern Afar (Ethiopia). Front. Earth Sci., 7, 351. 
Machado, G., 2020, Salt Biostratigraphy in Oil and Gas Exploration: An Untapped Source of Data?, Geoexpro, 17-1.

Magni, V., Bouilhol, P., Van Hunen, J., 2014, Deep water recycling through time, Geochem. Geophys. Geosyst., 15.

Manatschal, G., Lavier, L., Chenin, P., 2015, The role of inheritance in structuring hyperextended rift systems: Some considerations based on observations and numerical modeling, Gondwana Research, 27- 1, 140-164.

Manning, C. E., 2004, The chemistry of subduction-zone fluids, Earth and Planetary Science Letters, 223, 1-16.

Mart, Y., Ross, D., A., 1987, Post-Miocene rifting and diapirism in the northern Red Sea. Mar. Geol. 74, 173-190

McGary, R. S., Evans, R. L., Wanamaker, P. E., Elsenbeck, J., Rodenay, S., 2014, Pathway from subducting slab to surface for melt and fluids beneath Mount Rainier, Nature Research Letter, 511.

Mohriak, W., 2019, Rifting and Salt Deposition on Continental Margins: Differences and Similarities Between the Red Sea and the South Atlantic Sedimentary Basins, In: Geological Setting, Palaeoenvironment and Archaeology of the Red Sea, Najeeb M. A. Rasul, Ian C. F. Stewart, (Eds), Springer Nature Switzerland AG 2019, ISBN 978-3-319-99407-9.

Mukherjee, B. K., Sachan, H. K., 2009, Fluids in coesite-bearing rocks of the Tso Morari Complex, NW Himalaya: evidence for entrapment during peak metamorphism and subsequent uplift, Geol. Mag. 146 -6, 876-889.

Nurmillmo, P. A., Kukkonen Pertti,T., Lahermo, W., 1988, Geochemistry and origin of saline groundwaters in the Fennoscandian Shield, Applied Geochemistry, 3-2, 185-203.

Park, S. K., Ostos, L. C., 2013, Constraints from magnetotelluric measurements on magmatic processes and upper mantle structure in the vicinity of Lassen volcanic center, northern California, Geosphere, 9, No. 3, 382-393.

Petersen, K. D., Schiffer, C., 2016, Wilson cycle passive margins: Control of orogenic inheritance on continental breakup, Gondwana Research, 39, 131-144.

Petrunin, A. G., Kaban, M. K., E1 Khrepy, S., Al-Arif, N., 2020, Mantle Convection Patterns Reveal the Mechanism of the Red Sea Rifting. Tectonics, 39.

Pommier, A., and Evans, R.L., 2017, Constraints on fluids in subduction zones from electromagnetic data, Geosphere, 13, 4, 1026-1041, doi:10.1130/GES01473.1. 
Reid, I., 2003, Mantle flow and temperature during rifting: genesis of amagmatic continental margins, EGS - AGU - EUG Joint Assembly, Abstracts from the meeting held in Nice, France, 6 - 11 April 2003, abstract id. 13274.

Rupke, L. H., Schmid, D. W., Perez-Gussinye, M., Hartz, H., 2013, Interrelation between rifting, faulting, sedimentation, and mantle serpentinization during continental margin formation-Including examples from the Norwegian Sea, Geochem. Geophys. Geosyst.,14, $4351-4369$.

Samrock, F., Grayver, A. V., Bachmann, O., Karakas, Ö., Saar, M. O., 2020, Integrated magnetotelluric and petrological analysis of felsic magma reservoirs: Insights from Ethiopian rift volcanoes, Earth and Planetary Science Letters, 559, 116765.

Sanfilippo, A., (Merry) Yue Cai, Jácome, A. P. G., Ligi, M., 2019, Geochemistry of the Lunayyir and Khaybar Volcanic Fields (Saudi Arabia): Insights into the Origin of Cenozoic Arabian Volcanism. In: Geological Setting, Palaeoenvironment and Archaeology of the Red Sea, Najeeb M. A. Rasul, Ian C. F. Stewart, (Eds), Springer Nature Switzerland AG 2019, ISBN 978-3-319-99407-9.

Scambelluri, M., Piccardo, G. B., Philippot, P., Robbiano, A., Negretti, L., 1997, High salinity fluid inclusions formed from recycled seawater in deeply subducted alpine serpentinite, Earth and Planetary Science Letters, 148, 3-4, 485-499.

Schilling, F. R., Trumbull, R. B., Brasse, H., Haberland, C., Asch. G., Bruhn, D., Mai, K., Haak, V., Giese, P., Muoz, M., Ramelow, J., Rietbrock, A., Ricaldi, E., Vietor, T., 2006, Ch. 22- Partial melting in the Central Andean crust: A review of geophysical, petrophysical, and petrologic evidence, 459-474, In: Oncken, O., Chong, G., Franz, G., Giese, P., GÃutze, H. J., Ramos, V.A., Strecker, M. R., Wigger, P. (Eds.), The Andes: Active Subduction Orogeny, Frontiers in Earth Sciences, Springer, Berlin-Heidelberg, ISBN: 978-3-540-48684-8

Schwalenberg, K., Rath, V., Haak, V., 2002, Sensitivity studies applied to a two-dimensional resistivity model from the Central Andes, Geophys. J. Int.,150, 673-686.

Scribano, V., Carbone, S., Manuella, F. C., Hovland, M., Rueslåtten, H., Johnsen, H. K., 2017, Origin of salt giants in abyssal serpentinite systems, Int. J. Earth Sci., (Geol Rundsch), 106, 2595-2608.

Schmulovich, K., Graham, C., Yardley, B., 2001, Quartz, albite and diopside solubilities in $\mathrm{H}_{2} \mathrm{O}-\mathrm{NaCl}$ and $\mathrm{H}_{2} \mathrm{O}-\mathrm{CO}_{2}$ fluids at 0,5-0,9GPa, Contrib. Mineral Petrol. 141, 95-108.

Schofield, N., Alsop, I., Warren, J., Underhill, J. R., Lehné, R., Beer, W., Lukas, V., 2014, Mobilizing salt: Magma-salt interactions, Geology, published online on 22 May 2014 as doi:10.1130/G35406.1 
Shirey, S. B., Wagner, L. S., Walter, M. J., Pearson, D. G., \& van Keken, P. E., 2021, Slab transport of fluids to deep focus earthquake depths - thermal modeling constraints and evidence from diamonds, AGU Advances.

Sorensen, S. S., 1988, Petrology of amphibolite-facies mafic and ultramafic rocks from the Catalina Schist, southern California: metasomatism and migmatization in a subduction zone metamorphic setting, J. Metamorphic Geol., 6, 405-435.

Soret, M., Agard, P., Ildefonse, B., Dubacq, B., Prigent, C., Rosenberg, C., 2019, Deformation mechanisms in mafic amphibolites and granulites: record from the Semail metamorphic sole during subduction infancy, Solid Earth, 10, 1733-1755.

Stern, R. J., Johnson, P. R., 2019, Constraining the Opening of the Red Sea: Evidence from the Neoproterozoic Margins and Cenozoic Magmatism for a Volcanic Rifted Margin. In: Geological Setting, Palaeoenvironment and Archaeology of the Red Sea, Najeeb M. A. Rasul, Ian C. F. Stewart, (Eds), Springer Nature Switzerland AG 2019, ISBN 978-3-319-99407-9.

Stober, I., Bucher, K., 1999, Origin of salinity of deep groundwater in crystalline rocks, Terra Nova, 11, 181-185.

Stockli, D., F., Bosworth, W., 2019, Timing of Extensional Faulting Along the Magma-Poor Central and Northern Red Sea Rift Margin-Transition from Regional Extension to Necking Along a Hyperextended Rifted Margin.. In: Geological Setting, Palaeoenvironment and Archaeology of the Red Sea, Najeeb M. A. Rasul, Ian C. F. Stewart, (Eds), Springer Nature Switzerland AG 2019, ISBN 978-3-319-99407-9.

Stotler, R.L., Frape, S.K., Ruskeeniemi, T., Pitkanen, P., Blowes, D.W., 2012, The interglacial-glacial cycle and geochemical evolution of Canadian and Fennoscandian Shield groundwaters, Geochimica et Cosmochimica Acta, 76, 45-67.

Svensen, H., Jamtveit, B., Banks, D. A., Austrheim, H., 2001, Halogen contents of eclogite facies - uid inclusions and minerals: Caledonides, western Norway, J. Metamorphic Geol., 19, $165-178$.

Taviani, M., Montagna, P., Rasul, N. M. A., Angeletti, L., Bosworth, W., 2019, Pleistocene Coral Reef Terraces on the Saudi Arabian Side of the Gulf of Aqaba, Red Sea. In: Geological Setting, Palaeoenvironment and Archaeology of the Red Sea, Najeeb M. A. Rasul, Ian C. F. Stewart, (Eds), Springer Nature Switzerland AG 2019, ISBN 978-3-319-99407-9.

Timm, C., Davy, B., Haase, K., Hoernle, K., A., Graham, I., J., de Ronde, C., E.J., Woodhead, J., Bassett, D., Hauff, F., Mortimer, N., Seebeck, H., C., Wysoczansk, R., J., Caratori-Tontini, F., Gamble, J., A., 2014, Subduction of the oceanic Hikurangi Plateau and its impact on the Kermadec arc, NATURE COMMUNICATIONS, 4923, DOI: 10.1038/ncomms5923.

Tobola, T., 2016, Inclusions in anhydrite crystals from blue halite veins in the Klodawa Salt Dome (Zechstein, Poland), Geological Quarterly, 60-3, 572-585. 
Tobola, T., Wachowiak, J., 2018, Evidence of high-temperature rock salt transformations in areas of occurrence of borate minerals (Zechstein, Klodawa salt dome, Poland), Geological Quarterly, 62-1, 134-145.

Unsworth, M., 2015, Magnetotelluric studies of lithospheric structure beneath Western Canada: insights into plate tectonics both past and present, CSEG Recorder February 2015, 28-32.

Van Keken, P. E., Hacker, B. R., Syracuse, E. M., Abers, G. A., 2011, Subduction factory: 4. Depth-dependent flux of $\mathrm{H} 2 \mathrm{O}$ from subducting slabs worldwide, Journal of Geophysical Research, 116, B01401.

Wang, D., Guo, Y., Yu, Y., Karato, S., 2012, Electrical conductivity of amphibole-bearing rocks: influence of dehydration, Contrib. Mineral Petrol., 164, 17-25.

Wannamaker, P. E., Evans, R. L., Bedrosian, P. A., Unsworth, M. J., Maris, V., McGary, R. S., 2014, Segmentation of plate coupling, fate of subduction fluids, and modes of arc magmatism in Cascadia, inferred from magnetotelluric resistivity, Geochem. Geophys. Geosyst., 15, 4230-4253.

Watson, B., Brenan, J.M., 1987, Fluids in the lithosphere, 1. Experimentally-determined wetting characteristics of $\mathrm{CO}_{2}-\mathrm{H}_{2} \mathrm{O}$ fluids and their implications for fluid transport, hostrock physical properties, and fluid inclusion formation, Earth and Planetary Science Letters, 85-4, 497-515.

Wei, W-B., Jin, S., Ye, G-F., Deng, M., Tan, H-D., Unsworth, M., Jones, A. G., Booker, J., Li, S., 2006, Coductivity Structure of Crust and upper Mantle beneath the Northern Tibetan Platau: Results of Super-Wide Band Magnetotelluric Sounding, Chinese Journal of Geophysics, 49-4, 1-13.

Weis, P., 2015, The dynamic interplay between saline fluid flow and rock permeability in magmatic-hydrothermal systems, Geofluids, 15, 350-371.

Worzewski, T., Jegen, M., Kopp, H., Brasse, H., Taylor, W., 2010, Magnetotelluric image of the fluid cycle in the Costa Rican subduction zone, Nature Geoscience, 4,108-111.

Xu, Y., Yang, B., Zhang, S., Liu, Y., Zhu, L., Huang, R., Chen, C., Li, Y., Luo, Y., 2016, Magnetotelluric imaging of a fossil paleozoic intraoceanic subduction zone in western Junggar, NW China, J. Geophys. Res. Solid Earth, 121, 4103-4117.

Yan, Z., Chen, L., Xiong, X., Wang, K., Xie, R., Hsu, H., 2020, Observations and modeling of flat subduction and its geological effects, Science China Earth Sciences, 63, 1069-1091.

Yang, X., Keppler, H., McCammon, C., Ni, H., Xia, Q., Fan, Q., 2011, Effect of water on the electrical conductivity of lower crustal clinopyroxene, Journal of Geophysical Research, 116, B04208. 
Yao, Z., W. D. Mooney, H. M. Zahran, and S. E.-H. Youssef, 2017, Upper mantle velocity structure beneath the Arabian shield from Rayleigh surface wave tomography and its implications, J. Geophys. Res. Solid Earth, 122, 6552-6568, doi:10.1002/2016JB013805.

Zedgenizov, D. A., Ragozin, A. L., Shatsky, V. S., Chloride-Carbonate Fluid in Diamonds from the Eclogite Xenolith, Doklady Akademii Nauk, 2007, 415-6, 800-803.

Zhang, L., Wei, W-B., Jin, S., Ye, G., Dong, H., Zhang, F., Xie, C., Wang, H., 2013, Structure of the Eastern Margin of the Tibetan Plateau from Magnetotelluric Studies, Conference Paper, July 2013 DOI: 10.1190/nsgapc2013-093. 